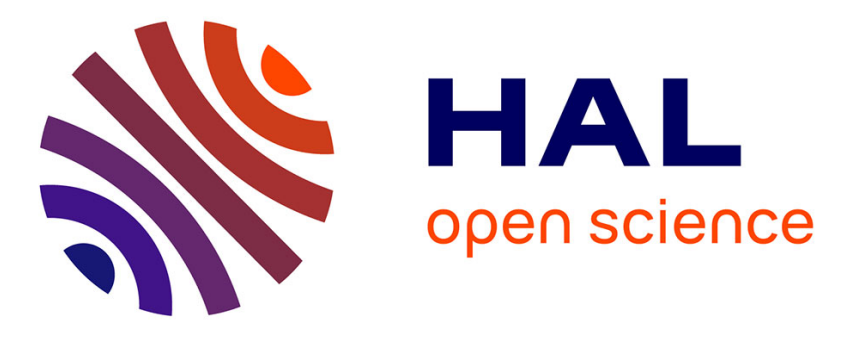

\title{
The Marsquake Service: Securing Daily Analysis of SEIS Data and Building the Martian Seismicity Catalogue for InSight
}

J. Clinton, D. Giardini, M. Böse, S. Ceylan, M. van Driel, F. Euchner, Raphaël F. Garcia, S. Kedar, A. Khan, S. C. Stähler, et al.

\section{To cite this version:}

J. Clinton, D. Giardini, M. Böse, S. Ceylan, M. van Driel, et al.. The Marsquake Service: Securing Daily Analysis of SEIS Data and Building the Martian Seismicity Catalogue for InSight. Space Science Reviews, 2018, 214 (133), pp.1-33. 10.1007/s11214-018-0567-5 . hal-01991048

\section{HAL Id: hal-01991048 https://hal.science/hal-01991048}

Submitted on 23 Jan 2019

HAL is a multi-disciplinary open access archive for the deposit and dissemination of scientific research documents, whether they are published or not. The documents may come from teaching and research institutions in France or abroad, or from public or private research centers.
L'archive ouverte pluridisciplinaire HAL, est destinée au dépôt et à la diffusion de documents scientifiques de niveau recherche, publiés ou non, émanant des établissements d'enseignement et de recherche français ou étrangers, des laboratoires publics ou privés. 


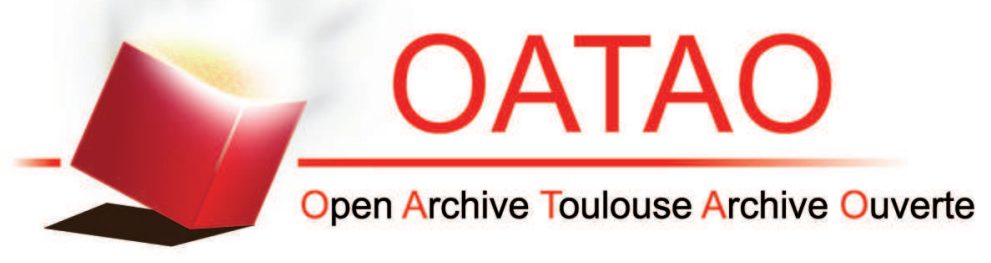

\section{Open Archive Toulouse Archive Ouverte (OATAO)}

OATAO is an open access repository that collects the work of some Toulouse researchers and makes it freely available over the web where possible.

This is an author's version published in: https://oatao.univ-toulouse.fr/21696

Official URL: https://doi.org/10.1007/s11214-018-0567-5

\section{To cite this version :}

Clinton, J. and Giardini, D. and Böse, M.,... [et al.] IThe Marsquake Service: Securing Daily Analysis of SEIS Data and Building the Martian Seismicity Catalogue for InSight. (2018) Space Science Reviews, 214 (133). 1-33. ISSN 0038-6308

Any correspondence concerning this service should be sent to the repository administrator: tech-oatao@listes-diff.inp-toulouse.fr 


\title{
The Marsquake Service: Securing Daily Analysis of SEIS Data and Building the Martian Seismicity Catalogue for InSight
}

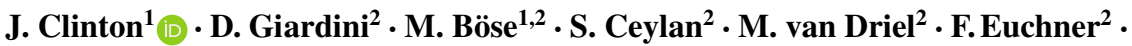 \\ R.F. Garcia ${ }^{3}$ - S. Kedar ${ }^{4}$ - A. Khan ${ }^{2}$ - S.C. Stähler ${ }^{2}$ B. Banerdt ${ }^{4}$ P. Lognonne ${ }^{5}$. \\ E. Beucler' • I. Daubar ${ }^{4}$ - M. Drilleau ${ }^{5}$ M. Golombek ${ }^{4}$ T. Kawamura ${ }^{5}$. \\ M. Knapmeyer ${ }^{7}$ - B. Knapmeyer-Endrun ${ }^{8}$ - D. Mimoun ${ }^{3}$ - A. Mocquet ${ }^{6}$ - M. Panning ${ }^{4}$. \\ C. Perrin ${ }^{5}$ N.A. Teanby
}

\begin{abstract}
The InSight mission expects to operate a geophysical observatory on Mars for at least two Earth years from late 2018. InSight includes a seismometer package, SEIS. The Marsquake Service (MQS) is created to provide a first manual review of the seismic data returned from Mars. The MQS will detect, locate, quantify and classify seismic events, whether tectonic or impact in origin. A suite of new and adapted methodologies have been developed to allow location and quantification of seismic events at the global scale using a single station, and a software framework has been developed that supports these methods. This paper describes the expected signals that will be recorded by SEIS, the methods used for their identification and interpretation, and reviews the planned MQS operational procedures. For each seismic event, the MQS will locate events using all available body and surface
\end{abstract}

\footnotetext{
J. Clinton

jclinton@sed.ethz.ch

1 Swiss Seismological Service, ETH Zurich, Zurich, Switzerland

2 Institute of Geophysics, ETH Zurich, Zurich, Switzerland

3 ISAE-SUPAERO, Toulouse University, Toulouse, France

4 Jet Propulsion Laboratory, California Institute of Technology, Pasadena, USA

5 Institut de Physique du Globe de Paris, Sorbonne Paris Cité, Paris VII-Denis Diderot University, CNRS, Paris, France

6 Laboratoire de Planétologie et Géodynamique, University of Nantes, CNRS UMR 6112, Nantes, France

7 DLR Institute of Planetary Research, Berlin, Germany

8 Seismological Observatory Bensberg, University of Cologne, Cologne, Germany

9 School of Earth Sciences, University of Bristol, Queens Road, Bristol, BS8 1RJ, UK
} 
phases, using the best estimates of the Martian structure, which will become more accurate as more Martian marsquakes are identified and located. The MQS will curate the Mars seismicity catalogue, with all events being relocated to use revised suites of structure models as they are introduced.

Keywords InSight $\cdot$ SEIS $\cdot$ Marsquakes $\cdot$ Martian seismicity $\cdot$ Impacts $\cdot$ Seismicity catalogue

\section{Introduction}

The InSight mission to Mars launched successfully on 5 May 2018, and will land a geophysical observatory on Mars on 26 November 2018. InSight includes a seismometer package, SEIS, consisting of a very broadband (VBB) seismometer and a short period (SP) seismometer with output acquired by the Ebox electronics (Lognonné et al. 2018, this issue). Also included are a heat probe ( $\mathrm{HP}^{3}$, Spohn et al. 2018, this issue) and a host of sensors that are part of the Auxiliary Payload Sensor Suite (APSS) that measures weather-related activity, including pressure, wind speed and direction, and temperature (Banfield et al. 2018, this issue). The nominal duration of the science phase of the mission is a full Martian year, approximately two Earth years.

InSight aims to understand the formation and evolution of terrestrial planets through investigation of the interior structure and processes of Mars and to determine its present level of tectonic activity and impact flux. To realise these goals there are a target set of basic scientific objectives, that have clearly measurable (L1) outcomes (Banerdt et al. 2013; Lognonné et al. 2018, this issue):

- Determine crustal thickness and structure

- Determine the crustal thickness to $\pm 10 \mathrm{~km}$

- Determine mantle composition and structure

- Detect any regional-scale crustal layering with velocity contrast $\geq 0.5 \mathrm{~km} / \mathrm{sec}$ over a depth interval $\geq 5 \mathrm{~km}$

- Determine the seismic velocities in the upper $600 \mathrm{~km}$ of mantle to within $\pm 0.25 \mathrm{~km} / \mathrm{sec}$

- Determine size, composition, and physical state of the core

- Positively distinguish between a liquid and solid outer core

- Determine core size to within $\pm 200 \mathrm{~km}$

○ Determine core density to within $\pm 450 \mathrm{~kg} / \mathrm{m}^{3}$

- Determine thermal state of the interior

- Determine the heat flux at the landing site to within $\pm 5 \mathrm{~mW} / \mathrm{m}^{2}$

- Measure the rate and distribution of internal seismic activity

- Determine the rate of seismic activity to within a factor of 2

- Determine epicentre distance to $\pm 25 \%$ and azimuth to $\pm 20^{\circ}$

- Measure the rate of meteorite impacts on the surface

- Determine the rate of meteorite impacts to within a factor of 2

The Marsquake Service (MQS) expects to create the basic seismicity catalogue for the mission that will count and characterise internal seismic and meteoroid activity, and will include many key markers that will allow determination of the additional objectives.

InSight will land in the western Elysium Planitia region of Mars at $4.5^{\circ} \mathrm{N}$ and $136.0^{\circ} \mathrm{E}$ (Golombek et al. 2017). Western Elysium Planitia lies just north of the global dichotomy 
boundary between elevated heavily cratered southern highlands and lower standing, less cratered, northern plains. The landing ellipse is mapped as Hesperian basalt flows that are smooth and flat with low rock abundance. Analysis of remote sensing data indicates the surface consists of an impact generated fragmented regolith 3-17 m thick composed dominantly of cohesionless sand that grades into coarse, blocky ejecta, overlying strong, jointed bedrock (Golombek et al. 2017). This relatively low density surficial unit with expected low seismic velocities will have an effect on recorded seismic waves (Knapmeyer-Endrun et al. 2017; Golombek et al. 2018).

In order to efficiently manage the data return and perform a rigorous and systematic first analysis, multiple services have been set up within InSight. For SEIS, the MQS will identify and characterise Martian seismicity and manage the subsequent seismic event catalogue; the Mars SEIS Data Service (MSDS) will curate and provide access to all scientific waveforms, associated metadata as well as the scientific products collected by SEIS; and the Mars Structure Service (MSS) will provide a-priori and updated models of the 1D and 3D planetary structure. Using APSS data, the Mars Weather Service (MWS) will analyse the weather signals and provide weather event information. These services will work in coordination with the various InSight Science Thematic Groups.

Data from SEIS is acquired and digitised on the Ebox (Lognonné et al. 2018, this issue), and is stored locally with a maximum sample rate of $100 \mathrm{sps}$. Limited communications with Mars means the amount of data that can be retrieved from InSight is constrained, and though SEIS data will have high priority, careful planning is required to decide the appropriate sampling rates from each channel that will be acquired in both continuous and event-request modes. In general, data will be received on Earth in twice daily chunks. The expected nominal communications budget allows $38 \mathrm{Mbits}$ or $4.75 \mathrm{MB}$ of data to be downloaded per sol (Martian day). Assuming all sensors are available as expected, during routine science operations, continuous data from all 3 components of the VBB will be retrieved at $2 \mathrm{sps}$, and a composite vertical channel derived from the VBB and SP sensors at $10 \mathrm{sps}$. A channel indicating the RMS of a band-passed composite of all components at 1 sps (ESTA) will provide an additional measure of the high frequency energy, with a bandpass nominally set between 3-7 Hz. Mass position channels from the VBB components, sensitive to longer periods, are acquired at $0.5 \mathrm{sps}$.

Weather data from APSS - temperature, wind speed and direction, pressure and magnetometer-and temperatures associated with SEIS sensors will also be transmitted in continuous chunks at lower sample rates.

The highest sample rate data channels are stored on the spacecraft in a roughly 3 week buffer. If interesting signals are identified or suspected in the continuous data streams, there is the capability to request segments of higher frequency data via 'Event Request Proposals' that are collected from the entire InSight community, including the Marsquake Service, evaluated together and prioritised during weekly meetings.

Once down-linked to Earth via the Deep Space Network (DSN), the waveform data from SEIS and the weather channels are collected at CNES in France and, via the SISMOC service, converted into miniSEED format, the seismic community standard. SISMOC also manages the creation of station metadata that accounts for changes in the seismometers/acquisition that may affect the data recorded. Metadata are curated using datalessSEED (SEED Manual 2012). SISMOC also has the capability to run a suite of processing scripts that can allow automatic cleaning of the data, for example removing the instrument response, de-glitching spikes, and decorrelating pressure, temperature and magnetic signals. Information that documents standard activity on the lander, such as power on/off, or operation of the robot arm, is also provided by SISMOC. Finally, SISMOC also performs automated detection targeting seismic events using Kurtosis filters. 
Data format conversion and processing at SISMOC will be completed within minutes of receiving the data from the DSN, and the data are then made available to project scientists and the various InSight services. MQS will automatically retrieve and archive the data and metadata provided by SISMOC and notify operators that new continuous and event data are available for inspection. The MQS does not rely on automated event triggers. Within a reasonable time-2 hours of the normal working day-the MQS team will then review all new waveforms, identify any seismic events, and notify the science team. The new catalogue is also available to the partner service, the Mars SEIS Data Service (MSDS) operated out of IPGP, which acquires the raw waveforms. Waveforms, seismic events and associated parameters will be available to the Science team immediately via the SEIS Data Portal (www.seis-insight.eu/), and after agreed delays, also to the general public.

The MQS also will closely liaise with the Mars Structure Service, which is responsible for determining improved models of the Martian interior.

The MQS aims to produce and manage a seismicity catalogue for the planet of Mars for the duration of the mission. It is a great challenge to be able to create a catalogue using a single station-we need to be able to identify all observed events, from the smallest local events close to SEIS to the moderate events SEIS aims to record from the other side of the planet. In anticipation of the launch, the MQS has developed numerous methods that can be used to locate and characterise the seismicity we expect to observe from SEIS. Any method that can be used for a given seismic event will be combined in a probabilistic framework to provide a best location (Böse et al. 2017). As we use a single station, the location is provided by determining epicentral distance and back-azimuth independently. With significant planetary ellipticity, major topographic features and the hemisphere dichotomy, the crust of Mars cannot be appropriately represented by a 1D structure. Thus our approach includes the ability to take into account the effect of 3D crustal effects (as estimated from gravity and topography) on surface waves as model sets can provide this level of detail. Magnitude scales like we use on Earth have been adapted to Mars (Böse et al. 2018). We have also developed tools to allow efficient management of the dataset, including facilitating manual screening of the data to aid first identification of events; labelling and timing of wave-types and specific arrivals; implementation of each method in our probabilistic framework, and services that allow management and display of various catalogues that will be provided, based on model sets that reflect our current best understanding of the planetary structure. We also have developed a tool that displays waveforms from all or selected seismic events included in the catalogue, allowing scientists to detect patterns among events with different distances, depths, azimuths or source types. In particular, this tool can provide some context when locating moderate marsquakes where first arrivals or different phases are obscured by noise.

The methods and procedures implemented at the Marsquake Service have been tested via a Blind Test that was held from July 2017-February 2018 (http://blindtest.mars.ethz.ch/, Clinton et al. 2017). In this test, the community was provided with an (Earth) year duration of seismic waveforms and was invited to produce a seismicity catalogue. The waveforms simulated an expected data return from Mars. They were generated by combining realistic Martian noise (Murdoch et al. 2017a, 2017b) with synthetic seismograms (Ceylan et al. 2017) generated from a randomly generated but representative Martian seismicity catalogue (including impacts) using a 1D velocity model that was not revealed to participants. Nine teams from across the globe, including one high school team and 2 masters-level classes, provided catalogues. The results are being combined into a journal article (van Driel et al. in preparation). The test allowed the MQS to exercise its procedures, benchmark performance, identify weak points, and develop new tools. 
The goal of the paper is to describe the Marsquake Service as we plan to operate it on Mars. We describe the character of the seismic data we expect to collect, including the types of seismic signals, and we present the current state-of-the art in our knowledge of the planetary structure before we collect data from InSight. We then describe the methods for detecting and locating seismic events, assigning magnitudes, discriminating source types and constraining source mechanisms that we intend to use in the routine, day-to-day investigation of the waveforms. We describe how the seismicity catalogue will be used to improve our understanding of the Martian interior. We conclude with a description of the planned operations for the MQS and provide outlook on additional methods that may be applied either within or outside the MQS activities.

The methods described in this paper assume that if seismic events are recorded by the InSight seismometers, they will more generally be more Earth-like than Moon-like. In the case of the Moon, the very strongly impacted and fractured regolith scatters seismic energy producing seismograms with very emergent, weakly polarised phases and long coda. If data is more Moon-like, or simply surprisingly different to the case on Earth, many methods proposed here will not work well, and we will have to react accordingly

\section{Towards the Martian Seismicity Catalogue}

InSight should return several years of continuous seismic data from Mars, possibly comprising records of meteoroid impacts, tectonic marsquakes, rock falls triggered by quakes, the hammering of the $\mathrm{HP}^{3}$ experiment (Spohn et al. 2014; Kedar et al. 2017), and also a range of meteorological and magnetic disturbances. The basic purpose of a seismicity catalogue is thus to provide metadata in order to support the retrieval of certain types of recordings. But its value reaches far beyond this.

On Earth, earthquake locations in catalogues delineate the boundaries of tectonic plates and the subduction of lithosphere, but also the existence of active areas within plates. The size-frequency distribution of catalogued events is the basis of seismic hazard analysis. On the Moon, deep moonquakes are tightly connected to tidal cycles, as revealed by the Lunar Long Period Event Catalog (Nakamura et al. 1981; Bulow et al. 2007; Weber et al. 2010). The same catalogue shows that impacts also cluster in time (Oberst and Nakamura 1991).

A seismicity catalogue is thus instrumental to understand the sources, causes, and processes of Martian seismicity, and to constrain the respective models.

\subsection{Expected Seismicity}

The relative geologic histories of the terrestrial planets argue that Mars should be seismically more active than the Moon, but less active than the Earth (Solomon et al. 1991; Oberst 1987; Goins and Lazarewicz 1979). From 1977 to 2013, the total seismic moment release per year varied $10^{21} \mathrm{Nm} / \mathrm{yr}$ to $10^{23} \mathrm{Nm} / \mathrm{yr}$ on the Earth (Global Centroid Moment Tensor catalog; Dziewonski et al. 1981; Ekström et al. 2012). Goins et al. (1981) found $10^{15} \mathrm{Nm} / \mathrm{yr}$ on the Moon. This would suggest a total moment release on Mars to be midway between the two or somewhere between $10^{17} \mathrm{Nm} / \mathrm{yr}$ and $10^{19} \mathrm{Nm} / \mathrm{yr}$ (Golombek 2002). The occurrence of 4-5 teleseismic tectonic events per year on the Moon (not tidally triggered, Nakamura 1980), suggests much higher seismicity than this on Mars. Furthermore, Mars has young fault scarps (Anderson et al. 2001, 2008), recent volcanic activity (Hartmann et al. 1999; Vaucher et al. 2009), and large uncompensated loads (Tharsis; e.g., Banerdt et al. 1992; Golombek and Phillips 2010), which all argue for significant present-day seismicity. Finally, 


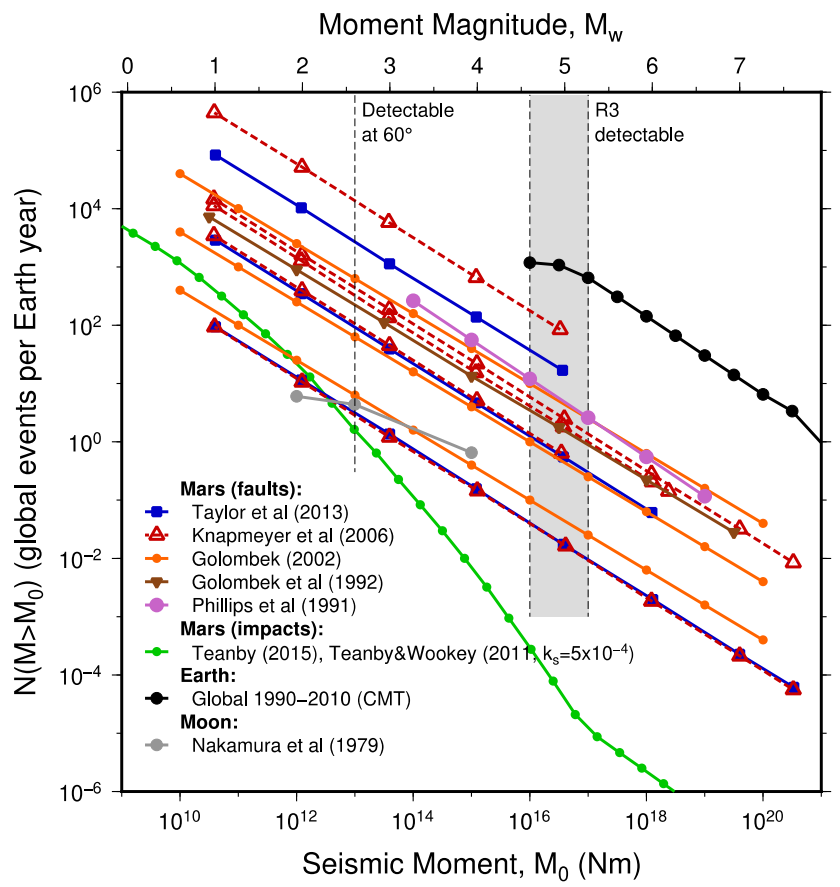

Fig. 1 Predictions of Martian seismicity in moment release, Mo versus cumulative number of events in an Earth year for faults and impacts. Mars faulting estimates (see Panning et al. 2017) are based on Phillips (1991), Golombek et al. (1992), Golombek (2002), Knapmeyer et al. (2006) (global) and Taylor et al. (2013) (Cerberus Fossae only). Mars impact seismicity is based on Teanby (2015)'s nominal regional estimates and Teanby and Wookey (2011)'s global estimates with a revised seismic efficiency of $k=5 \times 10^{-4}$. For comparison, the seismicity is also shown for the Moon (Nakamura et al. 1979) and Earth (whole globe from Harvard CMT catalogue). The dashed vertical line shows the predicted threshold magnitude for a $\mathrm{P}$ wave detection at $60^{\circ}$ distance based on the InSight seismometer performance and waveform modelling (Mocquet 1999; Teanby and Wookey 2011). The grey shaded area shows the approximate threshold magnitude and uncertainty for detection of the R3 surface wave (Panning et al. 2015). Both phase arrivals and multiple orbit R1/2/3 energy can be used to determine epicentral distance on Mars

although the Viking seismometer that functioned on Mars failed to unambiguously detect a marsquake, the poor sensitivity of the instrument on the lander does not preclude Mars from being seismically active (Anderson et al. 1977; Goins and Lazarewicz 1979).

Faulting, driven by internal cooling and large lithospheric loads such as Tharsis, is expected to be the dominant source of seismicity. Estimates based on predicted stress release from internal cooling (Phillips 1991; Knapmeyer et al. 2006; Plesa et al. 2017, 2018) and the area, total slip and age of surface faults (Golombek et al. 1992; Golombek 2002) both derive a total moment release for Mars of about $10^{18} \mathrm{Nm} / \mathrm{yr}$. The largest uncertainties in deriving recurrence intervals for different magnitude seismic events centre around the assumed negative power law slope of the number versus size of marsquakes and the largest possible marsquake (Golombek 1994). A weak crust can only support smaller stresses than a strong crust, so will tend to have more smaller events. Knapmeyer et al. (2006) explore these uncertainties and derive a variety of possible models that vary these parameters, and bracket the possibilities (Fig. 1).

Since the publication of these estimates of internal seismicity 10 to more than 20 years ago, members of the InSight science team re-evaluated all of the important factors and as- 
sumptions to see if advances in Mars science or seismology warranted an update. The team found that the most important factors that control the seismicity - the size of the largest possible marsquake, the slope of the negative power law that defines the number of marsquakes of any size, and the rigidity-were all within the bounds published by Knapmeyer et al. (2006). The previous estimates of moment release from the area, slip and age of surface faults (Golombek et al. 1992; Golombek 2002) were based on structures mapped in the western hemisphere of Mars (Anderson et al. 2001). A newer map of the eastern hemisphere is dominated by wrinkle ridges (Anderson et al. 2008), which also ring Tharsis in the northern plains (Withers and Neumann 2001; Head et al. 2002). These compressional structures formed mainly in the Hesperian and have been attributed to global thermal stresses (Mangold et al. 2000; Golombek and Phillips 2010). Inclusion of these structures would increase the number of faults and an adjustment of the assumed rigidity could increase the total moment release in the Hesperian by up to a factor of ten, which is within the two orders of magnitude uncertainty in the present-day estimate. Finally, members of the team published a new estimate of Mars seismicity from convective and cooling stresses derived from three-dimensional thermal evolution models of Mars and estimated likely variations in total moment release per year (Plesa et al. 2018). Results indicate a total moment release of $6 \times 10^{16}$ to $4 \times 10^{19} \mathrm{Nm} / \mathrm{yr}$, which is consistent with previous estimates, and the models make testable predictions of the pattern and depth of current seismicity that could be detected by SEIS (Plesa et al. 2017, 2018). Joint analysis of gravity and topography data (Gudkova et al. 2017) suggests a concentration of both extensional and shear stresses in the lithosphere beneath Hellas Planitia, Argyre Planitia, Mare Acidalium, and Valles Marineris, highlighting these as possibly active areas as well. Stress computation from convective mantle drag at the bottom of the lithosphere (Plesa et al. 2017, 2018) suggests that large events are more likely in the southern hemisphere.

The frequency of seismic events for the estimates of total seismic moment release per year and the slope of the negative power law that defines the number of marsquakes of any size have been determined for different assumed maximum marsquakes. Intermediate estimates suggest hundreds to thousands of marsquakes per year with seismic moments above $10^{13} \mathrm{Nm}$, which is approximately the minimum magnitude for detection of $\mathrm{P}$ waves at sufficient signal to noise ratio at epicentral distances up to $60^{\circ}$ (Mocquet 1999; Teanby and Wookey 2011; Böse et al. 2017; Clinton et al. 2017). In addition, there should be 4-40 teleseismic events (i.e., globally detectable) per year, which are estimated to have a seismic moment release of $\sim 10^{15} \mathrm{Nm}$, and 1-10 events per year large enough to produce detectable surface waves propagating completely around the planet, which are suitable for additional techniques in source location (Panning et al. 2015). An event large enough to create observable excitation of the planet's free oscillation (seismic moment of $\sim 10^{18} \mathrm{~N} \mathrm{~m}$ ) may be expected to occur during the nominal mission if the seismic activity level is near the upper bound of the range of reasonable estimates. In addition, hundreds to thousands of regional events per year around Tharsis should be expected, which offer a promising prospect for the SEIS investigation.

Of particular interest for InSight are the estimates for seismicity on Cerberus Fossae, one of the youngest tectonic features on Mars from which water carved catastrophic outflow channels (Burr et al. 2002) and from which lava covered a vast portion of Elysium Planitia (Plescia 1990; Jaeger et al. 2007; Vaucher et al. 2009). Cerberus Fossae has been interpreted as a long graben system (Vetterlein and Roberts 2010) with boulder trails young enough to be preserved in eolian sediments (Roberts et al. 2012), indicative of large and perhaps very recent marsquakes. Estimates of moment release based on the estimated fault area and slip indicate that recent marsquakes large enough to be recorded by the InSight instruments 
are likely (Taylor et al. 2013). Cerberus Fossae is only $\sim 1500 \mathrm{~km}$ northeast of the InSight landing site on Elysium Planitia.

\subsection{Expected Impacts}

Impact cratering will be another important source of seismic signals on Mars. We know that craters are forming currently from before and after images that constrain the appearance of new craters (Malin et al. 2006; Daubar et al. 2013). The current rates of crater formation match within a factor of $\sim 2-3$ the expected rates based on lunar cratering models, constrained by radiometric dates of returned samples, and then extrapolated to Mars (Hartmann 2005) These impact rates can be used to predict the sizes and frequencies of seismic signals from impacts (Teanby and Wookey 2011; Teanby 2015). However, these estimates include order-of-magnitude uncertainties stemming mainly from the poorly-constrained relationship between the impact energy and the magnitude of seismic waves produced, which is called the seismic efficiency. Thus any impact-induced seismicity predictions are uncertain to several orders of magnitude.

Given these large uncertainties, Teanby and Wookey (2011) predict only one large, globally detectable impact event every $\sim 1-10$ Earth years. However, smaller events that occur within the detection range of SEIS should occur $\sim 0.1-30$ times each Earth year (Teanby 2015). Using similar methods and an estimate of the likely noise levels of SEIS, Daubar et al. (2015) estimated 4-8 total impacts will be detected per Earth year by InSight.

Approximately half of new, dated impacts occur in clusters of craters that formed at the same time when the impactor fragmented in the atmosphere (Daubar et al. 2013); this will affect the seismic signal in ways currently being investigated, but will likely lower the number of detectable events (Daubar et al. 2017, 2018; Schmerr et al. 2016). The value of impacts as a seismic source therefore lies not in their frequency, but in our ability to locate them precisely on the surface of Mars (Daubar et al. 2018).

\subsection{Expected Noise}

The number of events that will be detected by InSight will be determined not only by the seismicity and impact rates as described above, but also by the character of the seismic signals generated by these events that actually reach InSight, as well as the actual background noise level seen by the SEIS instruments. The noise SEIS records is crucial in determining the limit of seismic event detectability. On Earth, site-characteristic noise is routinely determined and compared to global low- and high-noise models, and to the instrument performance (Peterson 1993 p. 93-95; Ringler and Hutt 2010), allowing for the derivation of detection thresholds. On Mars, in the absence of oceans, trees and anthropogenic noise, these noise models do not apply. We have developed for the InSight mission a specific Mars seismic noise model (Mimoun et al. 2017). This model includes the estimated contributions from the environment, such as the pressure noise, which is by far the dominating contributor to the noise environment (Murdoch et al. 2017a), the contributions from the lander, such as the wind-induced noise (Murdoch et al. 2017b) and the contribution of the SEIS instrument itself (self-noise) (Mimoun et al. 2017).

It is important to acknowledge the fact that major environmental contributors, such as the pressure tilt noise, change continuously from a state of low perturbation to high perturbation. During the night, wind and pressure variations will be smaller, as well as turbulence, leading to a very low environment noise: hence weaker seismic events may be detectable. In contrast, during daytime, and especially during bad weather (e.g. dust storms), there will 
be a higher noise, due to turbulence and the sensitivity of the seismometer to environment parameters.

We can simplify the external conditions into three categories of environmental noise: bad weather (about $30 \%$ of the total mission time), day (about $35 \%$ of the total mission time), and night (also 35\%). Noise budgets have then been evaluated for each category of environment, allowing potential characterisation of the limit of detectability for the catalogue with respect to the observed weather.

\subsection{Other Signals}

Evaluation of the seismic records from the Viking 2 seismometer (Anderson et al. 1977) has demonstrated the importance of non-seismic sources of vibration. This includes wind speed and magnetic field disturbances, but also activities of other spacecraft components. On Viking 2, motors, movements of the antennas, cameras and soil sampler were among the sources of noise, but also the length to which the soil sampler was extended made a difference. On the Moon, comparison of known astronaut activities with short period seismic data helped distinguishing events resulting from thermal stress in the Lunar Module from those resulting from thermal stress in the regolith (Duennebier and Sutton 1974).

Acoustic signals resulting from the $\mathrm{HP}^{3}$ penetration phase are considered as an active source for a dedicated experiment, requiring a record of the hammer timing (Kedar et al. 2017). Methods that use ambient noise to determine subsurface structure have been applied to the Apollo Lunar data (using events instead of noise due to the low noise level) (Mark and Sutton 1975; Nakamura et al. 1975; Larose et al. 2005). This class of approach will also be applied with InSight (Knapmeyer-Endrun et al. 2017) and will benefit from independent knowledge of wind speeds to choose the most suitable time windows.

\subsection{Seismotectonic Questions}

As on Earth, Martian seismicity is expected to reveal the seismic potential of visible fault systems. Most of them were formed more than $\approx 3 \mathrm{Ga}$ (Knapmeyer et al. 2006, and references therein), due to successive phases of extension and volcanism from the Noachian through the Amazonian (e.g. Anderson et al. 2001), while current active faulting would be more related to the global contraction as a result of the long-term cooling of the planet (Schubert and Spohn 1990; Schubert et al. 1993). Yet, several faults might have formed recently (i.e. < $10 \mathrm{Ma}$ ), possibly associated with recent volcanic activity (e.g. Neukum et al. 2004; Vaucher et al. 2009). Some of them could be active in the close vicinity of the landing site (Golombek et al. 2017), the best example being the Cerberus fault network, situated approximately $1500 \mathrm{~km}$ to the northeast of the landing site in Elysium Planitia (Taylor et al. 2013).

If the InSight seismicity catalogue includes accurate marsquake locations for many events, it can allow assessment of whether faults remain active, and will help to characterise their role in the deformation of Mars (i.e. crustal faults or shallow gravitational deformation). This is particularly true if faulting mode can be inferred from waveform inversion, but even without this information the slip mode can be inferred from the dominant fault types expressed at the surface in the province the event is locating in. If the actual deformation is governed by a global contraction of the planet, we can expect a higher activity of reverse faults (such as wrinkle ridges and lobate scarps; e.g. Knapmeyer et al. 2006), even if some normal faults could be reactivated in a reverse motion. The total moment release along the faults will be refined, then compared with previous studies which estimated annual seismic 
moment budget based on the fault traces observed at the surface (e.g., Golombek et al. 1992; Golombek 2002; Knapmeyer et al. 2006). Further, the structural maturity and frictional behaviour of faults, i.e. if they are creeping or fully locked, can be revealed by a high precision catalogue with many events.

Marsquake locations might be also helpful to define the stress distributions along and around the faults, compared to terrestrial fault systems. The Cerberus normal faults are $\sim 500 \mathrm{~km}$ long, significantly longer than any normal faults on Earth. Thus, it is important to understand how stress concentrates along faults and how the boundary conditions on Mars (e.g. curvature of the planet; gravity field; crustal thickness; rheology) can impact the fault growth and the fault structure (e.g. lateral segmentation, fault tip splay networks).

Ultimately, if a large marsquake ( $M>5-6)$ occurs along a Martian fault, its location as well as those from associated aftershocks can constrain the rupture development on Mars. Many studies describe the lateral segmentation along terrestrial faults and the role of intersegment zones which act as structural barriers to rupture propagation (e.g. Biasi and Wesnousky 2017; Manighetti et al. 2007; Stirling et al. 1996), and places where stress concentrations might also favour rupture initiation (e.g. Aki 1979; Barka and Kadinsky-Cade 1988; Manighetti et al. 2015; Shaw 2006). Faults on Mars are segmented (e.g. Schultz 2000; Smart et al. 2006; Polit et al. 2009; Vetterlein and Roberts 2010), and hence it is likely that the inter-segment zones also favour stress concentrations and affect the rupture development.

Statistical Parameter Estimation The estimations of the Martian tectonic seismicity level summarised above are all expressed in terms of event rate and seismic moment rate, i.e. parameters of the moment-frequency distribution of quakes. In its representation as survivor statistics, showing the number of events that exceed a certain seismic moment as function of that seismic moment, this distribution is usually described by the following parameters (see e.g. Kagan 2002, for a review of key statistical descriptions):

- completeness threshold: the catalogue is complete for events with moment larger than this (actually a property of the observer)

- slope: classically, the slope of the log-linear Gutenberg-Richter distribution

- corner moment: controls the largest seismic moment for which the distribution is loglinear; the precise meaning of the corner moment is dependent on the assumed type of distribution

- event rate: the number of seismic events per time interval

- moment rate: the seismic moment released per time interval

On Earth, the slope of the distribution appears to be independent of time and source region (e.g. Godano and Pingue 2000), with the possible exception of mid-oceanic ridges (Kagan 1997). Thermal moonquakes, on the other hand, release most energy at the small event end of the moment-frequency-distribution (Cooper and Kovach 1975), implying a much steeper distribution. The most recent Mars global seismicity models by Knapmeyer et al. (2006) and Plesa et al. (2017, 2018) assume that Martian seismicity follows Earth's standard slope. This might be challenging to prove, since Godano and Pingue (2000) conclude that a reliable slope estimate requires about 1000 events.

Event rate and moment rate both refer to long-term averages. The actual number of events e.g. in a given calendar year follows a Poisson distribution and, on Earth and evaluated from 1977 to 2013, varies by half an order of magnitude between years according to the GCMT (Global Centroid Moment Tensor catalogue Dziewonski et al. 1981; Ekström et al. 2012). The cumulative moment released during one calendar year is distributed around the long 
term average, and, in the above time interval of the GCMT, fluctuates by 1.5 orders of magnitude.

As Richter (1935) already found, the release of strain and energy due to quakes is dominated by the largest events. This is confirmed by moment rates derived from the GCMT: From 1977 to 2013, the two largest among the catalogued 40514 events released $31 \%$ of the catalogued seismic moment. Therefore it appears possible to obtain a reliable estimate of the moment rate from record breaking events only. A practical algorithm to do so will be described in a dedicated publication.

In summary, we expect that the Martian seismicity catalogue resulting from the InSight mission will be useful not only as an inventory of the dataset, but also to foster our understanding of the global tectonic regime.

\section{Models and Methods}

In order to locate seismic events across the entire planet using only a single station, several different techniques based on combinations of body-wave and surface wave arrivals are available (e.g. Böse et al. 2017). Application of these methods, however, is dependent on having available a suite of a priori models that span a range large enough to encompass all likely structure possibilities. These models can be used to precompute body and surface wave travel times. The a priori models are constructed using mineral physics data and include information on the bulk composition and temperature structure of Mars (e.g. Verhoeven et al. 2005; Rivoldini et al. 2011; Khan et al. 2018). In the following, we briefly discuss the construction of 1D models after which 3D models are described.

Radial (1D) model construction is described in detail in Khan et al. (2018). The procedure starts from a set of possible bulk model compositions that derive principally from geochemical and cosmochemical analyses of Martian meteorites and meteoritic material (Dreibus and Wänke 1984; Morgan and Anders 1980; Lodders and Fegley 1997; Sanloup et al. 1999; Taylor 2013). These bulk compositions are converted to geophysical models using phase equilibrium coupled with equation-of-state calculations to self-consistently produce models of $\mathrm{P}$ - and S-wave velocity and density as a function of composition, pressure, and temperature. Since Martian mantle temperatures are unknown, Khan et al. (2018) invert the currently available geophysical data stochastically (mean mass and moment of inertia and tidal response) for the main Martian parameters of interest (e.g. mantle composition and temperature and core size and composition). This procedure results in a wide range of Martian interior structure models that fit the geophysical observations. Armed with this set of models, travel times for various seismic body and surface wave phases as a function of epicentral distance and source depth can be generated and tabulated as look-up tables for subsequent use.

Constructing 3D models is more difficult given the little information we have on lateral variations in the interior of Mars. For this purpose, we mainly rely on high resolution surface topography maps and crustal thickness models that derive from inversion of gravity data (e.g. Neumann et al. 2004; Wieczorek and Zuber 2004; Plesa et al. 2016). While this provides some information on crustal structure, the question of lateral variations in seismic properties is not addressed. These have to be modelled through other means. A number of additional options are available that include (1) information on the composition of the surface as measured from gamma ray data (e.g. Taylor et al. 2006; Baratoux et al. 2014) and (2) results from geodynamical studies (e.g. Plesa et al. 2015, 2016). 
While major element chemistry of the Martian surface can be converted to geophysical properties, the approach suffers from the implicit assumption that crustal composition at depth is equal to the surface composition obtained from gamma ray data. This approach has been applied previously as a means of investigating the effect of lateral variations on seismic waveforms in regional models. The results showed that the effect due to surface and Moho topography is much larger than that obtained from a laterally varying surface composition (Bozdağ et al. 2017). Including results from geodynamical studies that model the evolution of Mars over 4.5 Gyr presents a potentially more interesting avenue in that variations are not limited to the crust, but span the entire mantle. In an initial attempt, we employ the thermal maps generated by Plesa et al. (2016) and, assuming chemical homogeneity throughout the Martian mantle, convert the temperature variations into geophysical properties (Bissig et al. 2018). The so modelled thermally-induced variations in seismic properties provide a means for estimating the effect lateral variations have on body and surface wave propagation and through that on travel times. While the analysis has only just begun, the impact is negligible on body wave travel times (a couple of seconds at most), but large on surface wave travel times (up to several hundred seconds). The implications of this variability for event location that relies on surface wave arrivals are therefore more dramatic and clearly require corrections to be applied prior to event location.

In practice, the MQS uses the TauP Toolkit (version 2.4.3; http://www.seis.sc.edu/TauP/) of Crotwell et al. (1999) to compute travel times for a predetermined suite of body wave phases as well as surface waves at various frequencies. Dispersion relations for fundamental mode surface waves are calculated using the minor-based code of Nolet (2008). Since the effects of 3D structure on body wave travel times are expected to be minor, TauP will continue to be our main tool for this purpose. We plan to apply 3D corrections for the surface wave travel times to account for crustal heterogeneities. In practice, travel time databases will need to be updated in order to be consistent with the currently preferred set of structure models. MQS will re-evaluate all previous locations using the new travel time databases computed for this new suite.

We mainly use synthetic waveforms to test our tools and methods described in this paper. For 1D case, we prefer to use the axisymmetric spectral element method AxiSEM (NissenMeyer et al. 2014) to generate Green's Functions databases (GF), and Instaseis (van Driel et al. 2015) to extract seismograms. Instaseis is a very efficient tool for computing seismograms for any type of arbitrary source at the order of seconds. For 3D case, we choose to use Salvus (Afanasiev et al. 2018).

\section{Locations}

To locate marsquakes and impacts during the InSight mission, the MQS will apply the probabilistic framework for single-station location developed by Böse et al. (2017) and implemented in the SeisComp3 Mars location GUI (marslocgui) tool developed by ETH Zurich and Gempa GmbH. This framework combines several approaches and different information in the seismic signals to determine the epicentral distance $\Delta$ and back azimuth $\Theta$ relative to the InSight seismometer as well as the source depth $h$; with the known lander location these estimates relative to the lander are converted into absolute event locations. If possible, locations of impacts will be independently verified and refined by high-resolution orbital images.

Single-station event locations are typically associated with great uncertainties that arise from the challenges of identifying seismic phases as well as unavoidable phase pick and 
model uncertainties. The probabilistic framework of Böse et al. (2017) characterises these uncertainties as probability density functions (PDFs). The framework currently combines four approaches, which are briefly described below. Details are given in Böse et al. (2017).

\subsection{Distance Estimation from Multi-Orbit Surface-Waves}

In this approach, the time delay between multi-orbit surface-wave arrivals is used to determine the epicentral distance and event origin time. If detectable, the MQS will use the first three multi-orbit arrivals of the Rayleigh wave, which propagate from the quake to the receiver along the minor arc of Mars, along the major arc, and along the minor arc plus an additional trip around the great circle path, respectively. The corresponding arrivals of $R 1, R 2$, and $R 3$ are picked from the waveform envelopes on the vertical component after applying a series of manually selected bandpass filters (Panning et al. 2015), which depend on the event distance and magnitude, and which typically range from 10 to 40 seconds. We expect the $R 1, R 2$ and $R 3$ phases to be detected for marsquakes at $10^{\circ}$ to $170^{\circ}$ distance and magnitudes of $\sim 5$ and greater, so will only be applicable for the largest events in the Mars catalogue. The approach requires no a priori velocity models. If extended to Love waves, it requires using horizontal components, which are expected to be noisier.

\subsection{Distance (and Depth) Estimation from Body- and Surface-Wave Phase Arrivals}

This method locates marsquakes and impacts from relative phase arrivals of body- and surface-waves while taking into account model and pick uncertainties. Model uncertainties are reflected by the use of a series of plausible 1D Mars models in the forward prediction of theoretical phase arrival times; pick uncertainties are specified by the data analyst. This location approach requires at least two phase picks: either two body- or one body-plus one surface-wave pick. As long as impulsive phases are recorded with a high signal-to-noise ratio, this approach can be applied to a variety of seismic events, including local events of all sizes as well as moderate regional and teleseismic events. In order to infer source depths, the MQS will use depth-sensitive phases, such as $P m P, \operatorname{SmP}, p P$ or $s P$, when identified, as well as relative amplitudes of body- and surface-waves.

The method is more robust when multiple phase types are observed. A location may still be estimated using P-wave and surface wave arrivals only, e.g. within an S-wave shadow zone.

This method can be extended to support 3D crust if there are candidate model suites. Travel times for longer period surface waves that are sensitive to 3D crustal variations are created for the azimuth segments of a selected angular size (we expect to use segments between $30-60^{\circ}$ ). If the back azimuth is known, events can be located using the azimuthspecific long period travel times.

Though this method can provide distance estimates for all events at any distance and magnitude as long as two phases can be identified, it works best when multiple phases are clearly identified. When phase onsets are within the noise, location accuracy is reduced, and when phases are mis-identified gross errors may result.

\subsection{Back Azimuth Estimation from Polarisation of Rayleigh Waves}

This method uses the polarisation of the $R 1$ wavetrain to estimate the back azimuth of the seismic event relative to the receiver by determining the angle of minimum cross-correlation 


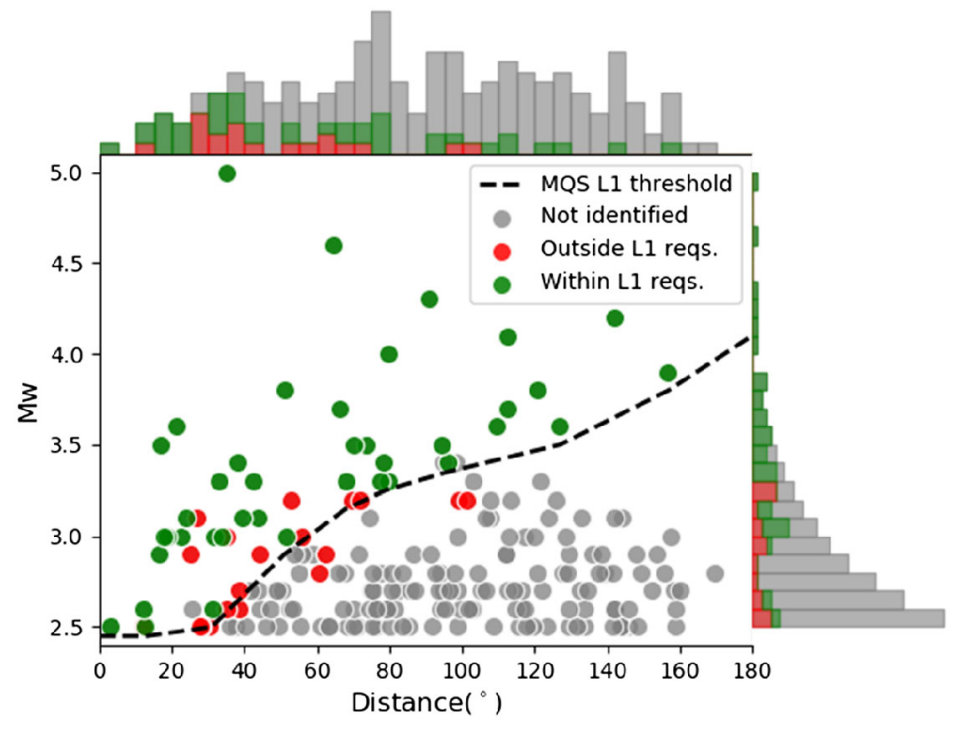

Fig. 2 Summary of seismic events included in the MQS Blind Test in terms of magnitude and distance from InSight lander. Events indicated in green and red were detected by MQS, those in grey were not identified (missed). Green events meet the InSight L1 requirements (located well), i.e. the estimated epicentral distances and back azimuths are within $\pm 25 \%$ and $\pm 20^{\circ}$ of the true location. Red events do not meet the L1 requirement (detected only). The black thick dotted line indicates the distance/magnitude detection threshold of the MQS for the Blind Test. Histograms on the top and right side indicate the proportion of events located well, detected only and missed in terms of magnitude and distance

between the radial and the Hilbert-transformed vertical components (e.g., Chael 1997). The approach requires $R 1$ energy and can be applied to a variety of event sizes and distances. On the Earth, the errors in back azimuth values derived by this method are typically on the order of $\sim 30^{\circ}$.

\subsection{Back Azimuth Estimation from the Polarisation of Body-Waves}

This method uses the polarisation of $\mathrm{P}$ or SV body-wave phases for back azimuth estimation. It can be applied to a variety of event sizes and distances, in particular to small local events.

All possible approaches will be used, depending on the quality of various observed seismic phases. The individual solutions are combined by the product of their PDFs, resulting in generally improved event location estimates and reduced uncertainties as compared to the results obtained from each algorithm. Tests with both synthetic marsquake waveforms and real earthquake recordings (Böse et al. 2017) suggest that the errors in event locations are small enough to meet the L1 requirements of the InSight mission, which require epicentral distances and back azimuths to be determined to accuracies of $\pm 25 \%$ and $\pm 20^{\circ}$, respectively (L1-SCI-51; Banerdt et al. 2013).

This location procedure above was exercised by the MQS team in their response to the Blind Test (Clinton et al. 2017), and the ability to meet L1 requirements was confirmed as shown in detail in Figs. 2 and 3. The MQS software interface itself is illustrated in Sect. 9 on Operations, using specific examples from the Blind Test. In Fig. 2 we summarise the ability of the MQS tools to locate different events at different distances.

The MQS will produce a catalogue that divides events into 3 quality types, and this was exercised in the Blind Test. Quality A are the best events, where either all 4 methods above 

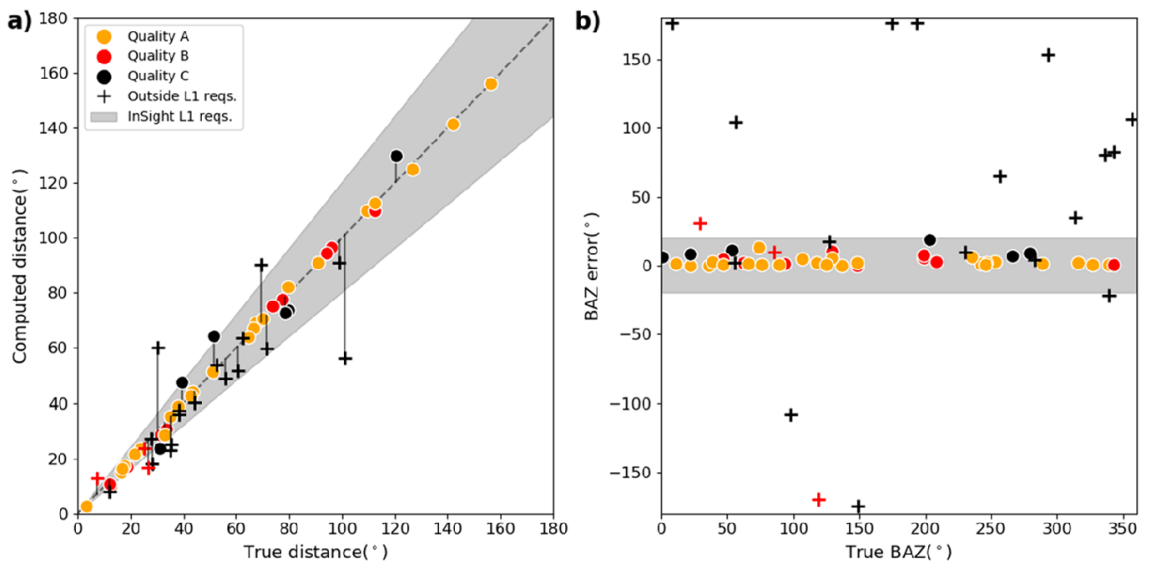

Fig. 3 Summary of performance of MQS event locations from the Blind Test in terms of (a) distance and (b) back-azimuth. The grey shaded areas indicate the region inside $\pm 25 \%$ of the true location (a) and $\pm 20^{\circ}$ of the true back-azimuth (b) (L1 requirements). Note all quality A and the majority of quality B events lie within the $\mathrm{L} 1$ requirements, and the majority are well within it. For distance, only a few quality B events that occur very close to the source are outside L1. For back azimuth, the handful of events clustering near $\pm 180^{\circ}$ have the wrong back azimuth selected because the body waves alone cannot resolve the ambiguity without knowing the first motion polarity

can be used, or the phase arrivals are clearly observed. Quality B events typically uses only phase arrivals for distance where the phase arrivals are often difficult to identify, and both methods are used for back azimuth. Quality $\mathrm{C}$ events are observed in the seismogram but it is very challenging to identify correct phases and back azimuth estimation may not be possible to accurately identify or only possible using a single phase type. In Fig. 3 we show that Quality A and B events meet the project requirements for the Blind Test.

In the future, other methodologies can be added to the probabilistic framework to further improve location estimates. Also likely marsquake locations, e.g. constrained by surface faults, may be included as prior information.

\section{Magnitudes}

The MQS will use a series of magnitude scales defined and calibrated by Böse et al. (2018), including a (1) local Mars magnitude, $M_{L}{ }^{M a}$, measured at periods of 3 seconds for marsquakes at distances of up to $10^{\circ}$; (2) P-wave magnitude, $m_{b}{ }^{M a}$ and (3) S-wave magnitude, $m_{b, s}{ }^{M a}$, each defined at periods of 3 seconds and calibrated for distances of up to $100^{\circ}$; (4) surface-wave magnitude, $M_{S}{ }^{M a}$, at periods of 20 seconds, (5) moment magnitudes, $M_{F B}{ }^{M a}$ and (6) $M_{F}{ }^{M a}$, calculated from the low-frequency (10-100 s period) plateau of the displacement spectrum for either body-waves or the full recording, respectively; the scales (4) to (6) are calibrated for distances of up to $180^{\circ}$. Note on Mars $1^{\circ}$ is $\sim 59 \mathrm{~km}$, where on Earth this distance is $111 \mathrm{~km}$. The high frequency period of 3 seconds is selected to enable magnitude calculation using the continuous data sampled at 2 sps.

In the absence of seismic observation data from Mars, Böse et al. (2018) calibrated these magnitude scales by simulating the seismic wave propagation through a set of realistic 1D Mars models. We expect these relations to be applied to the first seismic event catalogue of the InSight mission. Depending on the observed attenuation, scattering, and 3D effects, 
these relations may need to be updated as soon as observational data and new models become available. It is expected that marsquakes with moment magnitudes of less than 3 to 4 and epicentral distances of $\Delta>15^{\circ}$ will be hidden in the Mars background noise and probably not detectable (Böse et al. 2018). This is consistent with what is observed in the Blind Test data as seen in Fig. 2.

\section{Seismic Source Discrimination}

Although tectonic events are a key target, other event types may be seen on our seismic signals:

\subsection{Meteoroid Impacts}

Clear seismic traces of impacts on Earth have only been observed for very few events. In the Apollo seismometer experiment on Moon, however, impacts were the second-most common type of seismic sources, with over 1700 events in total. Since the Martian atmosphere is thinner than Earth's, it can be expected that the rate of seismically recordable impacts is somewhere between Earth and Moon, probably closer to the former. Impacts in the seismic dataset will be carefully studied by the science team (Daubar et al. 2018), but the Marsquake Service will have the task to rapidly identify impact candidates amongst the seismic events to allow rapid download of high-frequency data.

Impact sources differ from tectonic sources in two ways:

1. The source is a mixture of single force and explosion, in contrast to double-couple tectonic sources. This enhances lower frequencies as compared to the tectonic source (with a pre-factor of $\omega^{a}$, where $a<0$ depends on the ratio of single force to explosion).

2. The force source time function is a Dirac delta function, compared to the moment function of tectonic sources, which is a step function. This increases higher frequencies with a pre-factor of $\omega^{b}$, where $b \sim 1$.

The combination of those leads to a different spectrum for the P-wave train. Since the two effects go in opposite directions, automated detection using the spectra is not straightforward, but has been applied to the Apollo dataset before, as laid out in Daubar et al. (2018).

Other potential identifiers for impacts are:

- Depleted S-wave energy

- Relatively high surface wave amplitude

- Positive polarity of first P-motion

- Reverberations in the uppermost crustal layers, due to the very shallow source depth

None of these identifiers will be easy to detect or are unique to impacts, so the MQS will only present an initial identification of event types. Given the very high interest in seismic observation of impacts, especially for ones where a source crater may be identified, it can be expected that the impacts working group (IWG) will take over careful analysis.

\subsection{Atmospheric Activities}

Since the SEIS sensor is located directly on the surface, meteorological activities with a wide range of temporal and spatial scale will be visible in the seismic record, spanning global circulation with daily periods to local and sporadic whirlwinds known as dust devils. The 
latter are especially interesting, since their duration is comparable to tectonic events. Dust devils are moving local pressure depressions, similar to small tornadoes, tens of meters in diameter and have been observed in images of previous Mars landers (Metzger et al. 1999). The pressure depression generates tilt on the ground which can be detected on the seismic signal (Lorenz et al. 2015; Kenda et al. 2017). InSight is equipped with a pressure sensor, so dust devils close to the station will create coherent signals on the pressure sensor and seismometer and can be distinguished from tectonic events, which do not create correlated pressure signals. The MQS will report all clear Dust Devil observations, though the Mars Weather Service (MWS) is authoritative for identification of these events.

\subsection{Landslides}

Another non-traditional source are landslides (e.g. Yamada et al. 2013; Hibert et al. 2014). These events generate high frequency seismic signals whose source time function is tens to hundreds of seconds long. Since the landing site of InSight is far from regions with severe topography, seismic signatures of landslides are unlikely to be detectable.

\section{Source Investigations}

The analysis of source mechanisms is crucial to understanding tectonic activity. On Earth, focal mechanisms are used to infer the stress regime of whole regions. This information can augment the current limited knowledge on Martian tectonics from surface fault mapping (Golombek et al. 1992; Knapmeyer et al. 2006). Inversion for focal mechanisms, i.e. the orientation of the active fault and the direction of slip on it during the marsquake, can also improve the magnitude estimate, since it removes some of the uncertainty coming from the radiation pattern. If seismic phases that were reflected on the surface above the source can be identified, the depth of the event can be constrained reducing uncertainty on the focal mechanism. Determination of the focal mechanism will not be a routine task of the MQS for each event, since it needs clearly identified body wave phases with excellent signal-tonoise ratios, which may only be available for a handful of events. Two groups within the MQS will invert for focal mechanisms, using slightly different approaches. Both methods use body waveforms and assume that arrival times and phase types are known from the waveform analysis performed by MQS.

Single station inversion is challenging and its success relies on being able to model various phase arrivals. If arrivals are emergent and complex, as can occur if passing through fractured media that scatter signals, even if phases can be identified, it will be difficult to model these waveforms in any frequency band so it will not be possible to provide confident source solutions for any event. Further, inversions require good signal-to-noise for each phase, so solutions are likely only for a handful of the largest events in the catlaogue.

\subsection{PRISM}

The PRISM (PRobabilistic Inference of Source Mechanisms) method presented in Stähler and Sigloch $(2014,2016)$ infers depth and focal mechanisms or full moment tensors using the waveform of the P- and SH-wave train (P-pP-sP, S-sS). The Bayesian inference uses an empirical likelihood function based on a large test dataset of 2000 events above M5.8 recorded on Earth, with global distribution, from which 100000 body waveforms were 

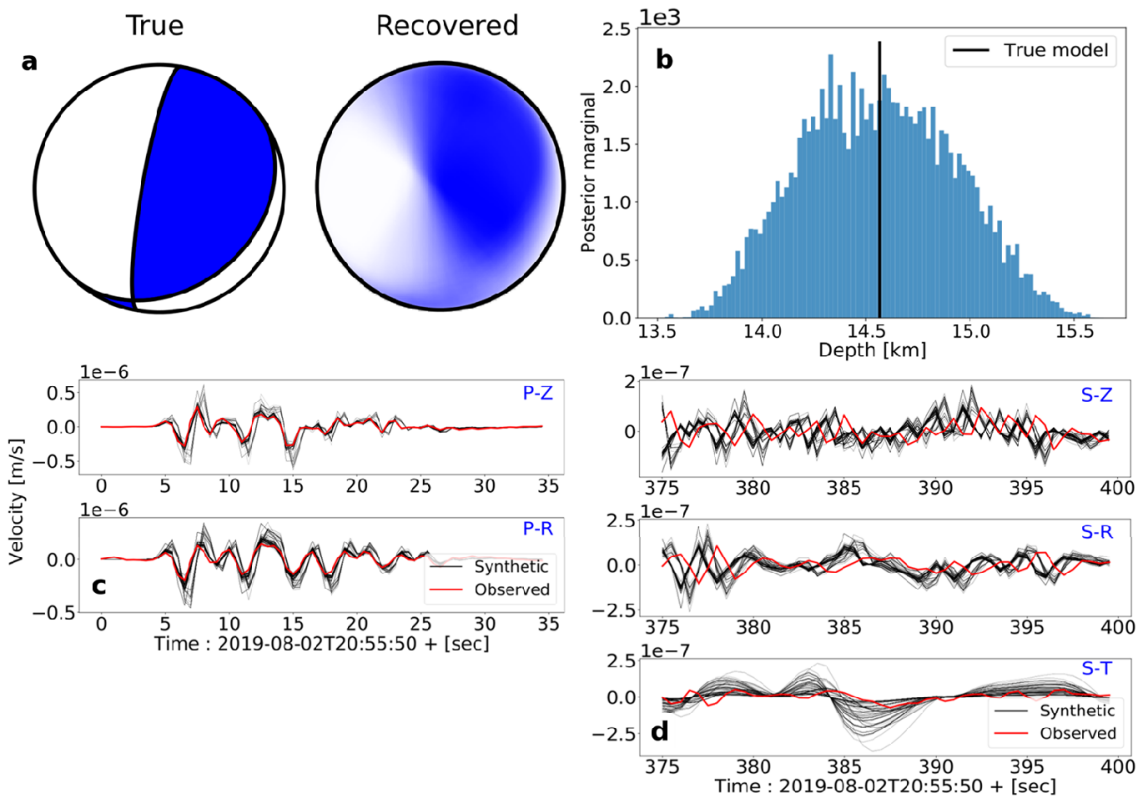

Fig. 4 Result of a probabilistic inversion for focal mechanism (strike, dip and rake), depth and epicentral distance for the 2019/08/02 event in the Mars Blind Test dataset. The 'Bayesian Beach Ball' is shown in (a), an overlay of the 1000 best fitting focal mechanisms. (b) shows the depth probability density. While the search was done between 5 and 35 kilometres, the algorithm converged around $14.5 \mathrm{~km}$. (c) shows the waveforms for the 1000 best fitting models. Note that the S-wave fit was generally very low, due to the low amplitude of $\mathrm{S}$-waves in the specific velocity model used for the blind test (d)

recorded, to obtain robust statistics on the expected level of fit. As a misfit, it uses the decorrelation between measured and simulated signal, which, for body waves, is relatively robust against modelling errors that arise from using incorrect crustal velocity models.

A test inversion, using the InSight Blind Test data (Clinton et al. 2017) was done, using Pand S-waveforms; geophysical arguments (Khan et al. 2018), suggest a high likelihood that $\mathrm{S}$-waves will have large shadow zones and low amplitudes for a large teleseismic distance range, so we allow for individual weights for each component of the P- and S-time window. Since a single P-waveform does not constrain all elements of the moment tensor, a priori information has to be added to the inversion, e.g. that the source can be described as a pure double couple, which reduces the number of free parameters of the moment tensor from 6 to 4 . Figure 4 shows that the P-waveform for an example event from the Mars Blind Test is sufficient to constrain the depth of the event, even though a wrong velocity model was deliberately used. In this example, the S-waveform is not visible above the noise. The inversion estimated the event to be of oblique thrust type, with poorly constrained strike angle. The true focal mechanism was indeed oblique thrust, but with a strike angle differing by $30^{\circ}$. If tectonic knowledge is available from dominant faulting in the province the event locates at, it can be introduced as prior information on strike angle.

\subsection{SAWIB}

The SAWIB code (Simulated WAveform Inversion of Body waves, Garcia et al. 2013) was used to estimate body wave travel time, amplitude and source time function of Earth data. To 

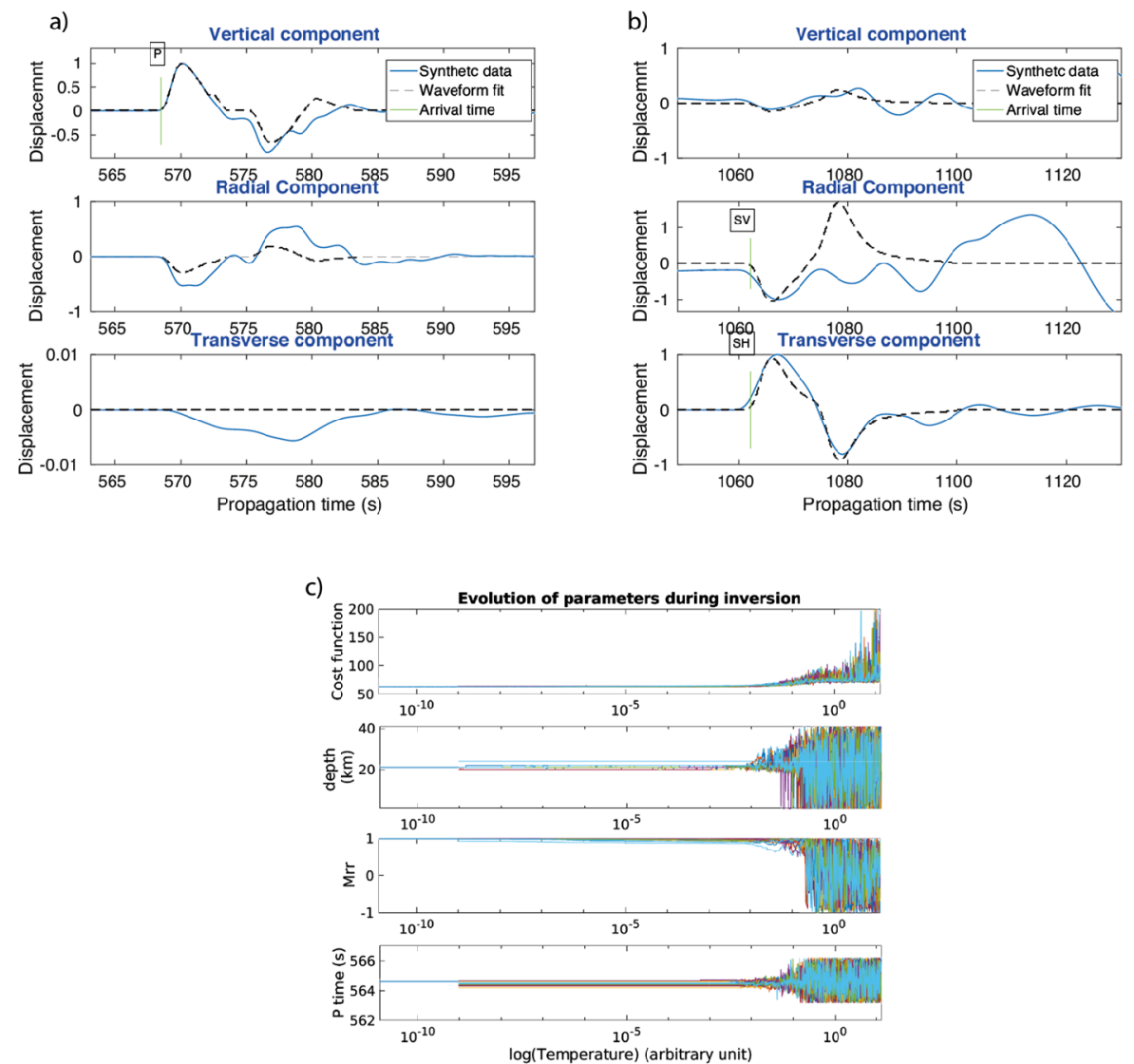

Fig. 5 Example SAWIB solution using synthetic seismograms from a Martian event $20 \mathrm{~km}$ deep quake at $90^{\circ}$ epicentral distance. Fits between observed synthetics and modelled data for the 3-components are shown for the P (a) and SV/SH (b) wave trains. Depth phases are included in the time windows. The evolution of key parameters of the inversion are shown in (c) - from top to bottom: cost function, event depth, one scaled component of moment tensor and $\mathrm{P}$ arrival time - as a function of simulated annealing temperature. Colours represent different inversion runs

compute body wave parameters it uses an extension of the Tau-P program, which takes into account ellipticity. The software is also improved by the analysis of the incidence angle and azimuth through the polarisation of the body waves. The free parameters of the waveform inversion are: 1. small time shifts between modelled body wave arrivals and data around the phase picks ( $<2$ seconds), 2. relative attenuation between $\mathrm{P}$ and $\mathrm{S}$ waves, 3. $\mathrm{P}$ waveform, used as proxy of event source time function, 3. event depth, 4. the six independent components of the moment tensor.

Figure 5 shows a test using synthetic, noise free Mars records from a $20 \mathrm{~km}$ deep marsquake at $90^{\circ}$ epicentral distance. The best inverted waveforms are presented in Fig. 5a and $5 \mathrm{~b}$, demonstrating the ability of the method to fit the waveforms in phase and amplitude, and to resolve the interference between direct and depth phases. The SV waveform fit appears to be more difficult due to interfering phases at the time of arrival of depth phases.

The evolution of some key parameters as a function of the temperature of the simulated annealing process is presented in Fig. 5c. Event depth is properly resolved as shown by 
the low variance between the various simulated annealing runs. However, the moment tensor, the relative attenuation between $\mathrm{P}$ and $\mathrm{S}$ waves and the magnitude estimate are either poorly constrained parameters or too dependent on both the internal structure model and the event/receiver geometry to consider these as resolved.

\section{Summary of MSS/MQS Joint Inversion Strategy}

Since source locations and structure models are inherently coupled, it will be important for the Marsquake Service and the Mars Structure Service to jointly invert for updated source locations and structure models. It is expected that the teams will work with at least 2 different "pipelines" to create model sets for probabilistic locations, which can lead to the creation of two associated location catalogues being curated concurrently. One set of models (called M1) will be created via Bayesian inversion of seismic data with models parameterised in velocity without applying any constraints from mineral physics. Another set, M2, will be created with models parameterised by (uniform) bulk composition and thermal profiles with seismic velocities calculated via mineral physics equations of state (e.g. Mocquet et al. 1996; Sohl and Spohn 1997; Verhoeven et al. 2005; Zharkov and Gudkova 2005; Rivoldini et al. 2011; Khan et al. 2008, 2018). The constraint of uniform composition can be relaxed in case more complexity is required. We use these two different approaches because each approach has certain strengths and weaknesses. Applying mineral physics constraints creates a strong prior constraint on the models and therefore can produce stable velocity models through the whole planet even with a very small number of recorded events (e.g., Khan et al. 2016). However, such constraints may be incorrect if, for example, there are non-equilibrium phase assemblages or composition is variable. The planned seismic observations to be used and the Bayesian inversion approach are detailed in Panning et al. (2017).

The general plan for the creation and updating of these two pipelines is shown in Fig. 6. Because there are no initial seismic observations to derive M1 models, the first set of events to be recorded will be located using a selection of a priori M2 models. As soon as sufficient observations from seismicity become available, a suite of M1 models will be created, and MQS will from then on begin to curate a new catalogue using the new family of models, with the already observed events being relocated. The weighting of the M2 models used in the probabilistic inversion scheme will also be updated based on the relative fit to the travel times across the event catalogue. This will reduce the location uncertainty as it reduces the impact of poorly matching models. From this point on, there will be two independent catalogues of marsquake locations based on these two pipelines. Periodically, when there is sufficient new data, MSS and MQS will perform a joint update of the models and relocation of all events. This can be accomplished within the same Bayesian inversion framework as the structure inversions. Location parameters will be allowed to vary in the Markov chain Monte Carlo (McMC) model generation scheme along with the structure parameters as illustrated in Khan et al. (2016). This will require an update of all the travel time tables utilised by MQS, and so will likely not be done after every event, but whenever significant new data become available.

It will also be necessary to periodically compare the families of M1 and M2 models. If the models deviate strongly from each other, that may indicate regions of the models that are either not well-constrained by the seismic data, or inconsistent with the physical assumptions of the M2 modelling approach. In the latter case, it may be necessary to update those physical assumptions, such as by allowing for non-equilibrium mechanical mixtures of end-member compositions, or composition that varies as a function of depth. 
Fig. 6 Flowchart of planned procedure for creation of model catalogues and joint updating of structure models and source locations. Boxes in red will only be performed periodically when significant new data become available

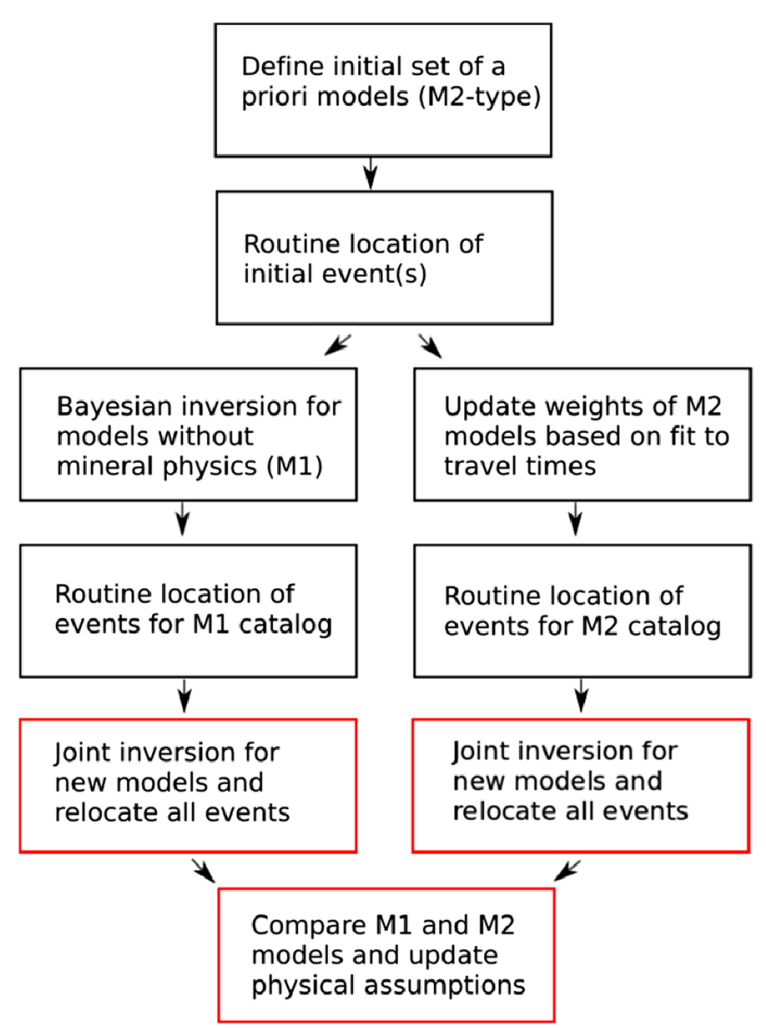

\section{Operations}

The Marsquake Service has created a software framework that supports manual review of the InSight data, detection, location and quantification of any observed seismicity, as well as catalogue management. The software is based on the popular SeisComP3 framework that is widely used by regional and global Seismic Networks across the Earth. This has been adapted to support our single station Martian methods with support from gempa $\mathrm{GmbH}$, who support SeisComP3. Although there is significant tailoring to account for the fact that InSight has a single station rather than a seismic network with many stations, the basic interactive SeisComP3 GUI we have developed is built following scolv (https://www.seiscomp3.org/doc/jakarta/current/apps/scolv.html), and is called the marslocgui. All the methods described in Sect. 4 on Locations and Sect. 5 on Magnitudes are supported in marslocgui. Basic extensions to the existing SeiComP3 data model have been made so that we can store single-station method metadata as well as to better support the complex catalogue requirements as outlined in Sect. 8.

In addition to the marslocgui, we have built another GUI that can display waveforms from multiple events ordered by epicentral distance, the marscatgui. By selecting events in terms of depth, location quality and epicentral distance and by filtering seismograms to accentuate different phase types, this GUI helps to identify similarities in the event waveforms, visually match manually picked seismic phases, theoretical arrival times and waveforms, and improve estimates of origin time, epicentral distance, depth and back azimuth, especially for weaker events with unclear onsets. It can also aid in distinguishing between impacts and tectonic events. 
The MQS will consist of 2 teams. A front-line team will take weekly turns to analyse all raw data coming from Mars as they arrive and to identify new seismicity. The review team will promptly review and if necessary revise events before they are released to the InSight science community. The MQS targets providing information about Martian events within a few hours following receipt of raw data.

\subsection{Event Detection-Marslocgui}

The marslocgui supports scrolling through and exploring all continuous and event channels returned from InSight, hence it is the primary tool for manual event detection. In addition to filtering waveforms, spectrograms and phase attributes (Tong and Kennett 1995) are included in order to aid event identification. The basic seismic channels at all available sampling rates are augmented by the pressure, wind speed and direction, temperature and magnetometer channels, housekeeping state of health data, as well as lander activity information (such as power on-off), in order to guide the operator to distinguish between lander or weather noise and seismic activity.

Figure 7 provides examples of different types of waveforms observed in the Blind Test. As can be seen in the images, some events are far easier to identify and locate. Nonetheless, all 3 events shown were located within the L1 requirements using the MQS tools.

\subsection{Event Location-Marslocgui}

Once an event is identified, the MQS person on front-line duty will attempt to make a location and provide a corresponding magnitude. If using a suite of $1 \mathrm{D}$ velocity models to determine event locations, it does not matter whether the epicentral distance or the backazimuth is first determined, although in order to best identify phases, once the back-azimuth is estimated then the horizontal waveforms can be rotated into radial and transverse components to aid phase identification. In the $3 \mathrm{D}$ case, it is crucial to first estimate the back azimuth in order to select long period surface wave travel-times (if these phases can be identified) from the appropriate back azimuth segment.

The additional channels and lander activity flags are also key information to be used by the operator to avoid incorrectly interpreting weather noise or lander activity as seismic energy.

Figure 8 shows a summary of the location for the M5.1 event in Fig. 7a. This is a large event with clear body and surface waves, including multiple orbits, so all methods are used to create the location. Since depth phases are not used, a default depth of $10 \mathrm{~km}$ is used.

If depth phases are observed, the depth is constrained by the Body waves method, otherwise the user must select a nominal depth. Without any assumed information on depth, a $10 \mathrm{~km}$ depth is used.

Every time a location is committed, a new origin will be created.

\subsection{Event Characterisation-Marslocgui}

Once a location is finalised but before an origin is created, a magnitude should be assigned. This is done using the magnitude tab in the marslocgui. All magnitudes described in Sect. 5 (and in detail in Böse et al. 2018) are automatically estimated for a given location, even if outside the recommended distance range for each magnitude. The preferred event depth and epicentral location are used without consideration of the uncertainty. The magnitude is calculated over the defined time windows with respect to manually identified phases if 
a) Ele Égir Yiew Navigation Bicking

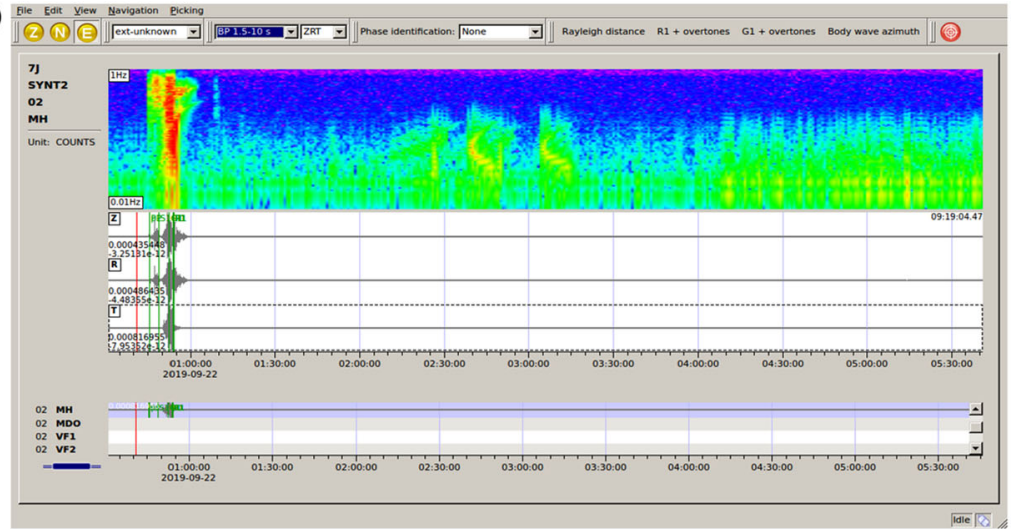

b)

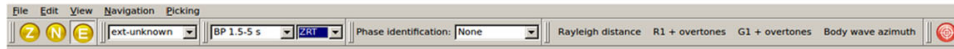

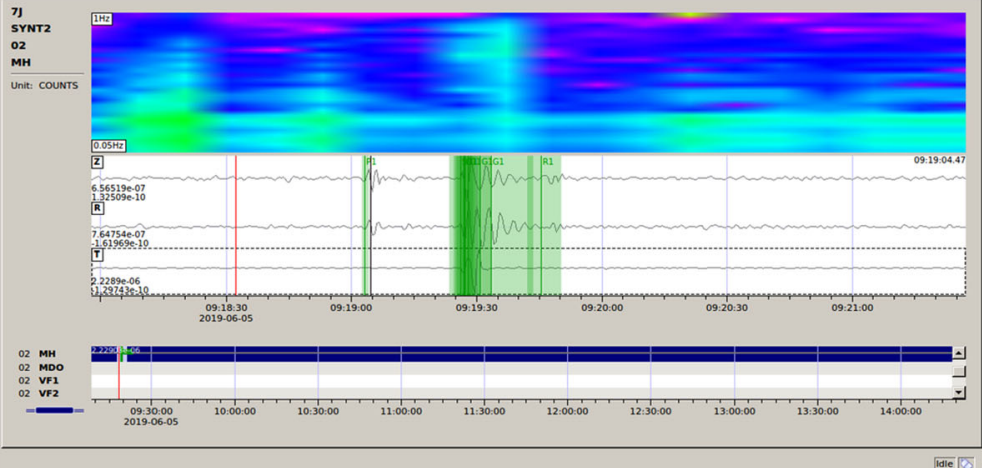

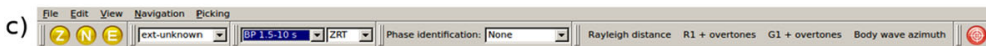

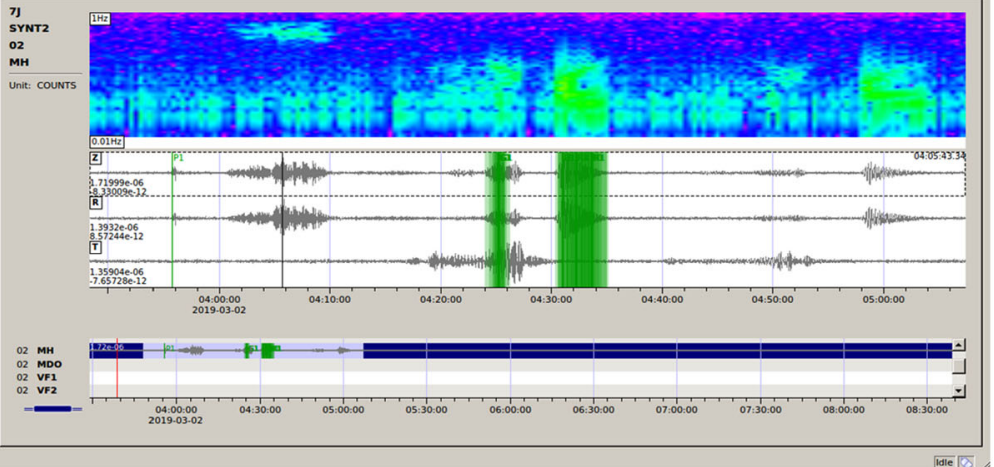

Fig. 7 Snapshots from the marslocgui picker window showing waveforms from selected events in the blind test: (a) M5.1 at $\sim 35^{\circ}$; (b) M2.5 at $\sim 3^{\circ}$, and (c) M4.3 at $\sim 140^{\circ}$. Note the very different time windows. Vertical component spectrograms and 3 component waveforms for the 2 sps VBB synthetics are shown at the top and middle respectively. On the bottom are all available channels which includes SP, VBB mass position, weather and housekeeping data as available. On the 3 component VBB waveforms, manual picks for body and surface waves made for each event are indicated by green vertical lines. The estimated origin time is shown on the red line. The first 2 events, the largest teleseism in the catalogue, and a major local event, have very high signal-to-noise and are well located with clear phases - the first event has clear multi-orbit surface waves. The last event is challenging to locate as phase arrivals are emergent and surface waves are weak 


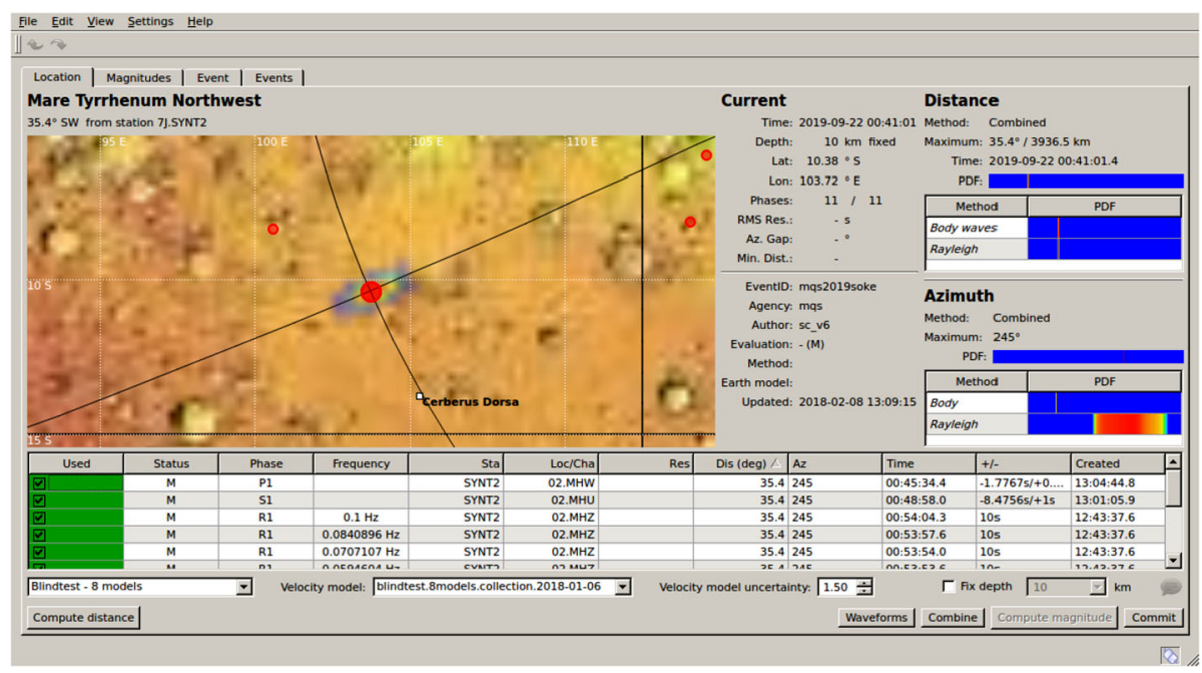

Fig. 8 Snapshot of the location summary from the marslocgui location tab for a M5.4 event from the Blind Test. The map shows the currently preferred location as the red dot at the intersection point of the two black lines that indicate preferred distance and back-azimuth. The colours around the epicentre indicate the location PDF. The additional red dots show other events already located in the catalogue. Background image is from Mars Orbiter Laser Altimeter (MOLA; Smith et al. 2001). On the right side of the image are summary PDF information from each method used for this location-the 2 algorithms for distance and azimuth are both used. For the distance, the PDF spans from $0-180^{\circ}$, it is clear both the phase-based ('Body waves') and multiple orbit Rayleigh wave ('Rayleigh') solutions provide very similar distance estimates of about $35^{\circ}$. Some of the phases that are used in the phase-based distance locator (Sect. 4.2) are shown in the lower table. The model suite used for the phase distance can be selected on the drop-down menu that currently shows 'Blindtest -8 models'. For the azimuth, the pdf spans from $0-360^{\circ}$. The body wave solution provides 2 peaks, at $65^{\circ}$ and $245^{\circ}$ (the latter is smaller amplitude so is not clearly visible). The Rayleigh wave back azimuth estimate is far less precise though there is no $180^{\circ}$ ambiguity, so when both PDF are combined the correct back azimuth is identified. The PDF in the map is produced by combining the 2 distance and 2 azimuth PDFs

they exist, using estimates from the travel time table from a selected velocity model if the required phase type has not been manually identified in the location. The user is able to view the component waveform on which the magnitude is computed, and change the default filters and/or time windows. The user can also select which magnitudes are stored and which one will be the preferred magnitude. A magnitude will be selected and assigned to every origin.

The source mechanism, as described in Sect. 7, is not routinely assigned by the MQS routine team, a source mechanism will be attempted depending on the quality of observed waveforms.

\subsection{Event Review-Marscatgui}

Once a sufficient number of events have been identified and characterised, the marscatgui can be a very useful tool to provide a sanity check on quality of each individual absolute location, and if needed, allow changes to the basic origin time and distance parameters. Depth and back azimuth can also be modified, although these are trickier to identity. Figure 9 indicates how events can be compared in context of the wider catalogue.

Manual phase picks and uncertainties can also be viewed (though not shown in Fig. 9) which can allow operators to identify mistakes in phase arrival time or even phase identification. 


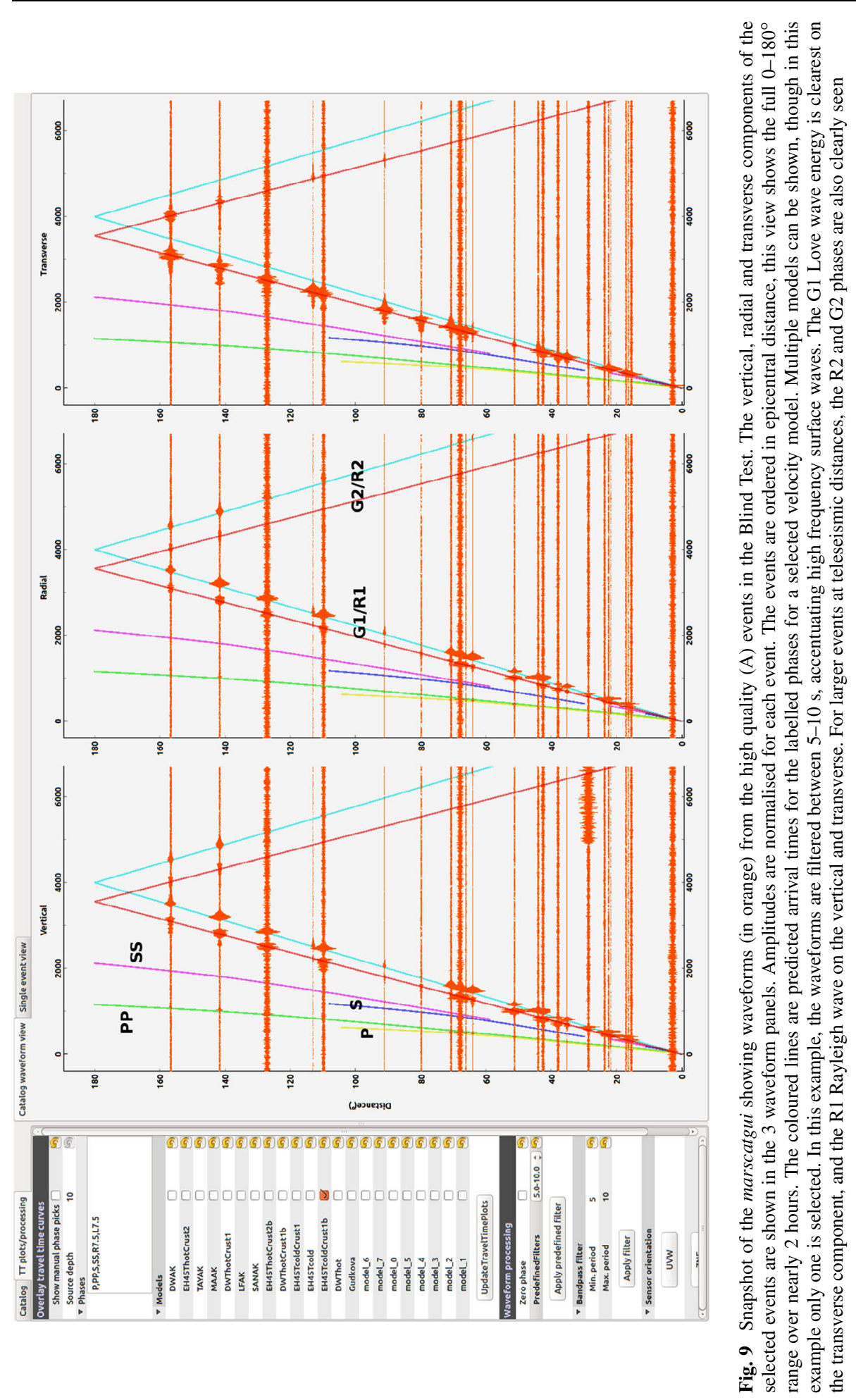




\subsection{Catalogue Management and Distribution to MSDS-Marslocgui}

Every on-duty operator can commit an origin once they have completed a location/magnitude. They then have the option to make any origin 'preferred', and once it has been verified by the review team, share it with the wider science team and the Mars SEIS Data Service (MSDS).

The MQS will define different catalogues, primarily based on the currently preferred suites of M1 and M2 velocity models (see Sect. 8), but they could also be based on e.g. contributors of phase picks.

The preferred set of M1 and M2 models will be periodically updated, in coordination with the MSS, depending on the quantity and quality of observed seismic events and/or other InSight-related science. Whenever this occurs, the on-duty team will take the responsibility to add these new model suites to the list of candidate models used in the marslocgui, and will also re-compute origins for existing events in using these models.

The MSDS is also responsible for distribution of the event to scientists outside the science team according to the schedule defined by the project. MQS does not release marsquake catalogues.

\subsection{Preparing Event Request Proposals (ERPs)}

If a seismic event is identified, there is an opportunity to request higher sample rate data in order to maximise the frequency content of the signals acquired on Earth from the event. The MQS will implement an automated strategy to requesting high frequency time windows depending on magnitude, distance, and suspected event type, also taking into account the available bandwidth.

The front-line team also take the responsibility to review all origins once high sample data become available, revising pick time, association and location as relevant.

\section{Outlook}

The MQS has built a robust operational framework that incorporates the latest methods for locating and characterising seismic events seen from SEIS and for curating resultant seismicity catalogues for the InSight project.

The MQS Blind Test (Clinton et al. 2017) allowed the MQS to demonstrate its ability to meet the key Mission requirements in terms of event location, though the test did have some shortcomings - the 1D velocity model resulted in overly simplistic seismograms; the fact the unknown 1D model was included in the suite of 14 candidate models meant that the model was easily identified using surface wave dispersion from the largest events; the release of all seismograms together meant each team was able to hunt for the largest events, use these to identify the model and understand the character of the seismograms under low noise, and work backwards to locate the smaller events. To address these issues, and to better exercise the planned 3D procedures, the MQS is conducting an MQS Operational Readiness Test (ORT) using 3D synthetics with a slow release catalogue shortly in advance of launch. This will be the final opportunity to exercise methods, software and procedures before landing.

Our tests so far used waveform synthetics that are created with the assumption that data will be more Earth-like than Moon-like. If InSight seismograms are characterised by scattering similar to that of the Moon, thus preventing standard arrival time estimation, the InSight goals on location accuracy may be challenging to meet. In any case, once we gain familiarity 
with the type of data we record on Mars, tools tailored to the observed waveforms will need to be developed in order to optimise our identification and classification of seismicity.

There are a number of potential tools we may explore incorporating in routine MQS operations. One method that combines event detection and classification is the application of a Hidden Markov Model-based automatic system. This method has been successfully applied to the complex lunar seismograms recorded by the Apollo stations, both on a global (Knapmeyer-Endrun and Hammer 2015) and a very local scale (Dimech et al. 2017), and has also been tested on a global terrestrial data set. Initially, the algorithm is trained to distinguish between different predefined types of events and noise based on a single prototype event for each event class and a sufficient amount of background noise. Then, it can be used to classify new data, including the potential to recognise novel event types that match neither the trained event models nor the noise model. This approach is well suited for a situation with little prior information and only a limited amount of event recordings available for training. A test on synthetic Mars data within the Blind Test led to promising first results.

Acknowledgements The authors would like to thank the editor and two reviewers who provided careful and critical reviews that substantially improved the manuscript. This work was jointly funded by (1) Swiss National Science Foundation and French Agence Nationale de la Recherche (SNF-ANR project 157133 "Seismology on Mars") and (2) Swiss State Secretariat for Education, Research and Innovation (SEFRI project "MarsQuake Service-Preparatory Phase"). Additional support came from the Swiss National Supercomputing Centre (CSCS) under project ID s682. Some of the research described in this article was supported by the InSight (Interior exploration using Seismic Investigations, Geodesy and Heat Transport) project, Jet Propulsion Laboratory, California Institute of Technology, under a contract with the National Aeronautics and Space Administration. We also thank A.-C. Plesa and V. Tsai for discussions on Mars seismicity and comments on an earlier draft. This article is InSight Contribution Number 57.

\section{References}

M. Afanasiev, C. Boehm, M. van Driel, L. Krischer, M. Rietmann, D.A. May, M.G. Knepley, A. Fichtner, Modular and flexible spectral-element waveform modeling in two and three dimensions. Geophys. J. Int. (2018). https://doi.org/10.1093/gji/ggy469/5174970

K. Aki, Characterization of barriers on an earthquake fault. J. Geophys. Res. 84, 6140-6148 (1979)

D.L. Anderson, W.F. Miller, G.V. Latham, Y. Nakamura, M.N. Toksöz, A.M. Dainty, F.K. Duennebier, A.R. Lazarewickz, R.L. Kovach, T.C.D. Knight, Seismology on Mars. J. Geophys. Res. 82(28), 4524-4546 (1977)

R.C. Anderson, J.M. Dohm, M.P. Golombek, A.F. Haldemann, B.J. Franklin, K.L. Tanaka, J. Lias, B. Peer, Primary centers and secondary concentrations of tectonic activity through time in the western hemisphere of Mars. J. Geophys. Res., Planets 106(E9), 20563-20585 (2001)

R.C. Anderson, J.M. Dohm, A.F.C. Haldemann, E. Pounders, M. Golombek, A. Castano, Centers of tectonic activity in the eastern hemisphere of Mars. Icarus 195, 537-546 (2008). https://doi.org/10.1016/j.icarus. 2007.12.027

W.B. Banerdt, M.P. Golombek, K.L. Tanaka, Stress and tectonics on Mars, in Mars, ed. by H.H. Kieffer, B.M. Jakosky, C.W. Snyder, M.S. Matthews (University of Arizona Press, Tucson, 1992), pp. 249-297. Chap. 8

W.B. Banerdt, S. Smrekar, P. Lognonné, T. Spohn, S.W. Asmar, D. Banfield, L. Boschi, U. Christensen, V. Dehant, W. Folkner, D. Giardini, W. Goetze, M. Golombek, M. Grott, T. Hudson, C. Johnson, G. Kargl, N. Kobayashi, J. Maki, D. Mimoun, A. Mocquet, P. Morgan, M. Panning, W.T. Pike, J. Tromp, T. van Zoest, R. Weber, M.A. Wieczorek, R. Garcia, K. Hurst, InSight: a Discovery Mission to explore the interior of Mars, in Lunar and Planetary Science Conference (2013). Lunar and Planetary Inst. Technical Report, 44,1915

D. Banfield, J.A. Rodriguez-Manfredi, C.T. Russell, K.M. Rowe, D. Leneman, H.R. Lai, P.R. Cruce, J.D. Means, C.L. Johnson, S.P. Joy, P.J. Chi, I.G. Mikellides, S. Carpenter, S. Navarro, E. Sebastian, J. Gomez-Elvira, J. Torres, L. Mora, V. Peinado, A. Lepinette, K. Hurst, P. Lognonné, S.E. Smrekar, W.B. Banerdt, InSight Auxiliary Payload Sensor Suite (APSS). Space Sci. Rev. (2018, this issue). https:// doi.org/10.1007/s11214-018-0570-x. 
D. Baratoux, H. Samuel, C. Michaut, M.J. Toplis, M. Monnereau, M. Wieczorek, R. Garcia, K. Kurita, Petrological constraints on the density of the Martian crust. J. Geophys. Res., Planets 119, 1707-1727 (2014). https://doi.org/10.1002/2014JE004642

A. Barka, K. Kadinsky-Cade, Strike-slip fault geometry in Turkey. Tectonics 7, 663-684 (1988). https:// doi.org/10.1029/TC007i003p00663

G.P. Biasi, S.G. Wesnousky, Bends and ends of surface ruptures. Bull. Seismol. Soc. Am. 107(6), 2543-2560 (2017). https://doi.org/10.1785/0120160292

F. Bissig, A. Khan, M. van Driel, S. Stahler, D. Giardini, M. Panning, M. Drilleau, P. Lognonné, T.V. Gudkova, V.N. Zharkov, W.B. Banerdt, On the detectability and use of normal modes for determining interior structure of Mars. Space Sci. Rev. (2018). https://doi.org/10.1007/s11214-018-0547-9

E. Bozdağ, Y. Ruan, N. Metthez, A. Khan, K. Leng, M. van Driel, M. Wieczorek, A. Rivoldini, C.S. Larmat, D. Giardini, J. Tromp, P. Lognonné, B.W. Banerdt, Simulations of seismic wave propagation on Mars. Space Sci. Rev. (2017). https://doi.org/10.1007/s11214-017-0350-z

M. Böse, J. Clinton, S. Ceylan, F. Euchner, M. van Driel, A. Khan, D. Giardini, P. Lognonné, W.B. Banerdt, A probabilistic framework for single-station location of seismicity on Earth and Mars. Phys. Earth Planet. Inter. 262, 48-65 (2017). https://doi.org/10.1016/j.pepi.2016.11.003

M. Böse, D. Giardini, S. Stähler, S. Ceylan, J. Clinton, M. van Driel, A. Khan, F. Euchner, P. Lognonné, B. Banerdt, Magnitude scales for marsquakes. Bull. Seismol. Soc. Am. (2018). https://doi.org/10.1785/ 0120180037

R.C. Bulow, C.L. Johnson, B.G. Bills, P.M. Shearer, Temporal and spatial properties of some deep moonquake clusters. J. Geophys. Res. 112, E09003 (2007). https://doi.org/10.1029/2006JE002847

D.M. Burr, J.A. Grier, A.S. McEwen, L.P. Keszthelyi, Repeated aqueous flooding from the Cerberus Fossae: evidence for very recently extant, deep groundwater on Mars. Icarus 159, 53-73 (2002). https://doi.org/ 10.1006/icar.2002.6921

S. Ceylan, M. van Driel, F. Euchner, A. Khan, J. Clinton, L. Krischer, M. Böse, S. Stähler, D. Giardini, From initial models of seismicity, structure and noise to synthetic seismograms for Mars. Space Sci. Rev. 211, 595 (2017). https://doi.org/10.1007/s11214-017-0378-0

E. Chael, An automated Rayleigh-wave detection algorithm. Bull. Seismol. Soc. Am. 87, 157-163 (1997)

J. Clinton, D. Giardini, P. Lognonné, B. Banerdt, M. van Driel, M. Drilleau, N. Murdoch, M. Panning, R. Garcia, D. Mimoun, M. Golombek, J. Tromp, R. Weber, M. Böse, S. Ceylan, I. Daubar, B. Kenda, A. Khan, L. Perrin, A. Spiga, Preparing for InSight: an invitation to participate in a blind test for Martian seismicity. Seismol. Res. Lett. 88, 1290-1302 (2017). https://doi.org/10.1785/0220170094

M.R. Cooper, R.L. Kovach, Energy, frequency, and distance of moonquakes at the Apollo 17 site, in Proc. 6th. Lunar Conf. (1975), pp. 2863-2879

H.P. Crotwell, T.J. Owens, J. Ritsema, The TauP toolkit: flexible seismic travel-time and ray-path utilities. Seismol. Res. Lett. 70, 154-160 (1999)

I.J. Daubar, A.S. McEwen, S. Byrne, M.R. Kennedy, B. Ivanov, The current Martian cratering rate. Icarus 225, 506-516 (2013). https://doi.org/10.1016/j.icarus.2013.04.009

I.J. Daubar, M.P. Golombek, A.S. McEwen, S. Byrne, M.A. Kreslavsky, N.C. Schmerr, M.E. Banks, Measurement of the current Martian cratering size frequency distribution, predictions for and expected improvements from InSight, in Lunar and Planetary Science Conference, vol. 46 (2015). Abstract 2468

I.J. Daubar, M.E. Banks, N.C. Schmerr, M.P. Golombek, W.K. Hartmann, E.C.S. Joseph, K. Miljković, O.P. Popova, N.A. Teanby, Crater clusters on Mars: implications for atmospheric fragmentation, impactor properties, and seismic detectability, in Lunar and Planetary Science Conference, vol. 48 (2017). Abstract 2544

I.J. Daubar et al., Impact-seismic investigations of the InSight mission. Space Sci. Rev. (2018). https:// doi.org/10.1007/s11214-018-0562-X

J.-L. Dimech, B. Knapmeyer-Endrun, D. Phillips, R.C. Weber, Preliminary analysis of newly recovered Apollo 17 seismic data. Results Phys. 7, 4457-4458 (2017)

G. Dreibus, H. Wänke, Accretion of the Earth and the inner planets, in Proc. 27th International Geol. Conf., vol. 11 (1984), pp. 1-20

F. Duennebier, G.H. Sutton, Thermal moonquakes. J. Geophys. Res. 79(29), 4351-4363 (1974)

A.M. Dziewonski, T.-A. Chou, J.H. Woodhouse, Determination of earthquake source parameters from waveform data for studies of global and regional seismicity. J. Geophys. Res. 86, 2825-2852 (1981). https:// doi.org/10.1029/JB086iB04p02825

G. Ekström, M. Nettles, A.M. Dziewonski, The global CMT project 2004-2010: centroid-moment tensors for 13,017 earthquakes. Phys. Earth Planet. Inter. 200-201, 1-9 (2012). https://doi.org/10.1016/j.pepi. 2012.04.002

R.F. Garcia, L. Schardong, S. Chevrot, A nonlinear method to estimate source parameters, amplitude, and travel times of teleseismic body waves. Bull. Seismol. Soc. Am. (2013). https://doi.org/10.1785/ 0120120160 
C. Godano, F. Pingue, Is the seismic moment-frequency relation universal? Geophys. J. Int. 142, 193-198 (2000)

N.R. Goins, A.R. Lazarewicz, Martian seismicity. Geophys. Res. Lett. 6, 368-370 (1979). https://doi.org/ 10.1029/GL006i005p00368

N.R. Goins, A.M. Dainty, M.N. Toksöz, Seismic energy release of the Moon. J. Geophys. Res. 86, 378-388 (1981)

M.P. Golombek, W.B. Banerdt, K.L. Tanaka, D.M. Tralli, A prediction of Mars seismicity from surface faulting. Science 258(5084), 979-981 (1992). https://doi.org/10.1126/science.258.5084.979

M.P. Golombek, Constraints on the largest marsquake, in Lunar Planet. Sci. Conf., vol. XXV (1994), pp. 441442

M.P. Golombek, A revision of Mars seismicity from surface faulting, in Lunar Planet. Sci. Conf., vol. XXXIII (2002). Abstract 1244

M.P. Golombek, R.J. Phillips, Mars tectonics, in Planetary Tectonics, ed. by T.R. Watters, R.A. Schultz (Cambridge University Press, Cambridge, 2010), pp. 183-232

M. Golombek, D. Kipp, N. Warner, I.J. Daubar, R. Fergason, R.L. Kirk, R. Beyer, A. Huertas, S. Piqueux, N.E. Putzig, B.A. Campbell, G.A. Morgan, C. Charalambous, W.T. Pike, K. Gwinner, F. Calef, D. Kass, M. Mischna, J. Ashley, C. Bloom, N. Wigton, T. Hare, C. Schwartz, H. Gengl, L. Redmond, M. Trautman, J. Sweeney, C. Grima, I.B. Smith, E. Sklyanskiy, M. Lisano, J. Benardini, S. Smrekar, P. Lognonné, W.B. Banerdt, Selection of the InSight landing site. Space Sci. Rev. 211, 5-95 (2017). https://doi.org/10.1007/s11214-016-0321-9

M. Golombek, M. Grott, G. Kargl, J. Andrade, J. Marshall, N. Warner, N.A. Teanby, V. Ansan, E. Hauber, J. Voigt, R. Lichtenheldt, B. Knapmeyer-Endrun, I.J. Daubar, D. Kipp, N. Müller, P. Lognonné, C. Schmelzbach, D. Banfield, A. Trebi-Ollennu, J. Maki, S. Kedar, D. Mimoun, N. Murdoch, S. Piqueux, P. Delage, W.T. Pike, C. Charalambous, R. Lorenz, L. Fayon, A. Lucas, S. Rodriguez, P. Morgan, A. Spiga, M. Panning, T. Spohn, S. Smrekar, T. Gudkova, R. Garcia, D. Giardini, U. Christensen, T. Nicollier, D. Sollberger, J. Robertsson, K. Ali, B. Kenda, W.B. Banerdt, Geology and physical properties investigations by the InSight lander. Space Sci. Rev. (2018). https://doi.org/10.1007/s11214-018-0512-7

T.V. Gudkova, A.V. Batov, V.N. Zharkov, Model estimates of non-hydrostatic stresses in the Martian crust and mantle: 1. Two-level model. Sol. Syst. Res. 51(6), 457-478 (2017)

W.K. Hartmann, Martian cratering 8: isochron refinement and the chronology of Mars. Icarus 174, 294-320 (2005). https://doi.org/10.1016/j.icarus.2004.11.023

W.K. Hartmann, M. Malin, A. McEwen, M. Carr, L. Soderblom, P. Thomas, E. Danielson, P. James, J. Veverka, Evidence for recent volcanism on Mars from crater counts. Nature 397, 586-589 (1999)

J.W. Head III., M.A. Kreslavsky, S. Pratt, Northern lowlands of Mars: evidence for widespread volcanic flooding and tectonic deformation in the Hesperian period. J. Geophys. Res. 107(E1), 5003 (2002). https://doi.org/10.1029/2000JE001445

C. Hibert, G. Ekström, C.P. Stark, Dynamics of the Bingham Canyon Mine landslides from seismic signal analysis. Geophys. Res. Lett. 41, 4535-4541 (2014). https://doi.org/10.1002/2014GL060592

W.L. Jaeger, L.P. Keszthelyi, A.S. McEwen, C.M. Dundas, P.S. Russell, Athabasca Valles, Mars: a lavadraped channel system. Science 317, 1709-1711 (2007). https://doi.org/10.1126/science.1143315

Y.Y. Kagan, Seismic moment-frequency relation for shallow earthquakes: regional comparison. J. Geophys. Res. 102(B2), 2835-2852 (1997)

Y.Y. Kagan, Seismic moment distribution revisited: I. Statistical results. Geophys. J. Int. 148, 520-541 (2002)

S. Kedar, J. Andrade, B. Banerdt, P. Delage, M. Golombek, M. Grott, T. Hudson, A. Kiely, M. Knapmeyer, B. Knapmeyer-Endrun, C. Krause, T. Kawamura, P. Lognonné, T. Pike, T. Spohn, N. Teanby, J. Tromp, J. Wookey, Analysis of regolith properties using seismic signals generated by InSight's HP3 penetrator. Space Sci. Rev. 211, 315-337 (2017). https://doi.org/10.1007/s11214-017-0391-3

B. Kenda, P. Lognonné, A. Spiga, T. Kawamura, S. Kedar, W.B. Banerdt, R. Lorenz, D. Banfield, M. Golombek, Modeling of ground deformation and shallow surface waves generated by Martian dust devils and perspectives for near-surface structure inversion. Space Sci. Rev. 211.1-4, 501-524 (2017). https://doi.org/10.1007/s11214-017-0378-0

A. Khan, J.A.D. Connolly, S.R. Taylor, Inversion of seismic and geodetic data for the major element chemistry and temperature of the Earth's mantle. J. Geophys. Res. 113, B09308 (2008). https://doi.org/10. 1029/2007JB005239

A. Khan, M. van Driel, M. Böse, D. Giardini, S. Ceylan, J. Yan, J. Clinton, F. Euchner, P. Lognonné, N. Murdoch, D. Mimoun, M. Panning, M. Knapmeyer, W.B. Banerdt, Single-station and single-event marsquake location and inversion for structure using synthetic Martian waveforms. Phys. Earth Planet. Inter. 258, 28-42 (2016). https://doi.org/10.1016/j.pepi.2016.05.017

A. Khan, C. Liebske, A. Rozel, A. Rivoldini, J.A.D. Connolly, A.-C. Plesa, D. Giardini, A geophysical perspective on the bulk composition of Mars. J. Geophys. Res. (2018). https://doi.org/10.1002/ 2017JE005371 
M. Knapmeyer, J. Oberst, E. Hauber, M. Wählisch, C. Deuchler, R. Wagner, Working models for spatial distribution and level of Mars' seismicity. J. Geophys. Res. 111, E11006 (2006). https://doi.org/10. 1029/2006JE002708

B. Knapmeyer-Endrun, M.P. Golombek, M. Ohrnberger, Rayleigh wave ellipticity modeling and inversion for shallow structure at the proposed inSight Landing Site in Elysium Planitia, Mars. Space Sci. Rev. 211(1-4), 339-382 (2017). https://doi.org/10.1007/s11214-016-0300-1

B. Knapmeyer-Endrun, C. Hammer, Identification of new events in the Apollo 16 lunar seismic data by hidden Markov model-based event detection and classification. J. Geophys. Res. 120, 1620-1645 (2015). https://doi.org/10.1002/2015JE004862

E. Larose, A. Khan, Y. Nakamura, M. Campillo, Lunar subsurface investigated from correlation of seismic noise. Geophys. Res. Lett. 32, L16201 (2005). https://doi.org/10.1029/2005GL023518

K. Lodders, B. Fegley, An oxygen isotope model for the composition of Mars. Icarus 126, 373-394 (1997)

P. Lognonné, W.B. Banerdt, D. Giardini, W.T. Pike, U. Christensen, P. Laudet, S. de Raucourt, P. Zweifel, S. Calcutt, M. Bierwirth, K.J. Hurst, F.I. Jpelaan, J.W. Umland, R. Llorca-Cejudo, S. Larson, R. Garcia, S. Kedar, B. Knapmeyer-Endrun, D. Mimoun, A. Mocquet, M.P. Panning, R.C. Weber, A. Sylvestre-Baron, G. Pont, N. Verdier, L. Kerjean, L.J. Facto, V. Gharakanian, J.E. Feldman, T.L. Hoffman, D.B. Klein, K. Klein, N.P. Onufer, J. Paredes-Garcia, M.P. Petkov, J.R. Willis, S.E. Smrekar, M. Drilleau, T. Gabsi, T. Nebut, O. Robert, S. Tillier, C. Moreau, M. Parise, G. Aveni, S. Ben Charef, Y. Bennour, T. Camus, P.A. Dandonneau, C. Desfoux, B. Lecomte, O. Pot, P. Revuz, D. Mance, J. ten Pierick, N.E. Bowles, C. Charalambous, A.K. Delahunty, J. Hurley, R. Irshad, H. Liu, A.G. Mukerherjee, I.M. Standley, A.E. Stott, J. Temple, T. Warren, M. Eberhardt, A. Kramer, W. Kühne, E.-P. Miettinen, M. Monecke, C. Aicardi, M. André, J. Baroukh, A. Borrien, A. Bouisset, P. Boutte, K. Brethomé, C. Brysbaert, T. Carlier, M. Deleuze, J.M. Desmarres, D. Dilhan, C. Doucet, D. Faye, N. Faye-Refalo, R. Gonzalez, C. Imbert, C. Larigauderie, E. Locatelli, L. Luno, J-R. Meyer, F. Mialhe, J.M. Mouret, M. Nonon, Y. Pahn, A. Paillet, P. Pasquier, G. Perez, R. Perez, L. Perrin, B. Pouilloux, A. Rosak, I. Savin de Larclause, J. Sicre, M. Sodki, N. Toulemont, B. Vella, C. Yana, F. Alibay, O. Avalos, M. Balzer, P. Bhandari, E. Blanco, B.D. Bone, J. Bousman, P. Bruneau, F. Calef, R.J. Calvet, S. D’Agostino, G. de los Santos, R. Deen, B. Denise, J. Ervin, N. Ferraro, H.E. Gengl, F. Grinblat, D. Hernandez, M. Hetzel, M. Johnson, L. Khachikyan, J. Lin, S. Madzunkov, S. Marshall, L. Mikellides, E.A. Miller, W. Raff, J. Singer, C. Sunday, J. Villalvazo, M.C. Wallace, D. Banfield, J.A. Rodriguez-Manfredi, C.T. Russell, A. TrebiOllennu, J.N. Maki, E. Beucler, M. Böse, C. Bonjour, J.L. Berenguer, S. Ceylan, J. Clinton, V. Conajero, I. Daubar, V. Dehant, P. Delage, F. Euchner, I. Estève, L. Fayon, L. Ferraioli, C. Johnson, J. GagnepainBeyneix, M. Golombek, A. Khan, T. Kawamura, B. Kenda, P. Labrot, N. Murdoch, C. Pardo, C. Perrin, L. Pou, A. Sauron, D. Savoie, S. Stähler, E. Stutzman, N.A. Teanby, J. Tromp, M. van Driel, M. Wieczorek, R. Widmer-Schnidrig, J. Wookey SEIS (eds.), The seismic experiment for internal structure of InSight. Space Sci. Rev. (2018, this issue)

R.D. Lorenz, S. Kedar, N. Murdoch, P. Lognonné, T. Kawamura, D. Mimoun, W.B. Banerdt, Seismometer detection of dust devil vortices by ground tilt. Bull. Seismol. Soc. 105(6), 3015-3023 (2015). https:// doi.org/10.1785/0120150133

M.C. Malin, K.S. Edgett, L.V. Posiolova, S.M. McColley, E.Z.N. Dobrea, Present-day impact cratering rate and contemporary gully activity on Mars. Science 314, 1573-1577 (2006). https://doi.org/10.1126/ science. 1135156

N. Mangold, P. Allemand, P.G. Thomas, G. Vidal, Chronology of compressional deformation on Mars: evidence for a single and global origin. Planet. Space Sci. 48, 1201-1211 (2000)

I. Manighetti, M. Campillo, S. Bouley, F. Cotton, Earthquake scaling, fault segmentation, and structural maturity. Earth Planet. Sci. Lett. 253, 429-438 (2007). https://doi.org/10.1016/j.eps1.2006.11.004

I. Manighetti, C. Caulet, D. De Barros, C. Perrin, F. Cappa, Y. Gaudemer, Generic along-strike segmentation of Afar normal faults, East Africa: implications on fault growth and stress heterogeneity on seismogenic fault planes. Geochem. Geophys. Geosyst. 16, 443-467 (2015). https://doi.org/10.1002/2014GC005691

N. Mark, G.H. Sutton, Lunar shear velocity structure at Apollo Sites 12, 14, and 15. J. Geophys. Res. 80(35), 4932-4938 (1975). https://doi.org/10.1029/JB080i035p04932

S.M. Metzger, J.R. Carr, J.R. Johnson, T.J. Parker, M.T. Lemmon, Dust devil vortices seen by the Mars Pathfinder camera. Geophys. Res. Lett. 26(18), 2781-2784 (1999). https://doi.org/10.1029/ 1999GL008341

D. Mimoun, N. Murdoch, P. Lognonné, K. Hurst, W.T. Pike, J. Hurley, T. Nébut, W.B. Banerdt, The noise model of the SEIS seismometer of the InSight mission to Mars. Space Sci. Rev. 211(1-4), 383-428 (2017). https://doi.org/10.1007/s11214-017-0409-x

A. Mocquet, A search for the minimum number of stations needed for seismic networking on Mars. Planet. Space Sci. 47, 397-409 (1999)

A. Mocquet, P. Vacher, O. Grasset, C. Sotin, Theoretical seismic models of Mars: the importance of the iron content of the mantle. Planet. Space Sci. 44, 1251-1268 (1996) 
J.W. Morgan, E. Anders, Chemical composition of Earth, Venus, and Mercury. Proc. Natl. Acad. Sci. USA 77(12), 6973-6977 (1980)

N. Murdoch, B. Kenda, T. Kawamura, A. Spiga, P. Lognonné, D. Mimoun, W.B. Banerdt, Estimations of the seismic pressure noise on Mars determined from Large Eddy Simulations and demonstration of pressure decorrelation techniques for the InSight mission. Space Sci. Rev. (2017a). https://doi.org/10.1007/ s11214-017-0343-y

N. Murdoch, D. Mimoun, R.F. Garcia, W. Rapin, T. Kawamura, P. Lognonné, D. Banfield, W.B. Banerdt, Evaluating the wind-induced mechanical noise on the InSight seismometers. Space Sci. Rev. (2017b). https://doi.org/10.1007/s11214-016-0311-y

Y. Nakamura, Shallow moonquakes: how they compare with earthquakes, in Proc. Lunar Planet. Sci. Conf., vol. 11 (1980), pp. 1847-1853

Y. Nakamura, J. Dorman, F. Duennebier, D. Lammlein, G. Latham, Shallow lunar structure determined from the passive seismic experiment. Earth Moon Planets 13, 57 (1975). https://doi.org/10.1007/ BF00567507

Y. Nakamura, G. Latham, H. Dorman, A.B. Ibrahim, J. Koyama, P. Horvarth, Shallow moonquakes-depth, distribution and implications as to the present state of the lunar interior, in Proc. Lunar Planet. Sci. Conf., vol. 10 (1979), pp. 2299-2309

Y. Nakamura, G.V. Latham, H.J. Dorman, J.E. Harris, Passive seismic experiment, long-period event catalog. Final version, Tech. Rep. 18, Inst for Geophys. Univ. of Texas, Galveston (1981)

G. Neukum, R. Jaumann, H. Hoffmann, E. Hauber, J.W. Head, A.T. Basilevsky, B.A. Ivanov, S.C. Werner, S. van Gasselt, J.B. Murray, T. McCord, Recent and episodic volcanic and glacial activity on Mars revealed by the high resolution stereo camera. Nature 432, 971-979 (2004). https://doi.org/10.1038/nature03231

G.A. Neumann, M.T. Zuber, M.A. Wieczorek, P.J. McGovern, F.G. Lemoine, D.E. Smith, Crustal structure of Mars from gravity and topography. J. Geophys. Res. 109, E08002 (2004). https://doi.org/10.1029/ 2004JE002262

T. Nissen-Meyer, M. van Driel, S.C. Stähler, K. Hosseini, S. Hempel, L. Auer, A. Colombi, A. Fournier, AxiSEM: broadband 3-D seismic wavefields in axisymmetric media. Solid Earth 5, 425-445 (2014). https://doi.org/10.5194/se-5-425-2014

G. Nolet, A Breviary of Seismic Tomography (Cambridge University Press, Cambridge, 2008)

J. Oberst, Unusually high stress drops associated with shallow moonquakes. J. Geophys. Res. 92, 1397-1405 (1987)

J. Oberst, Y. Nakamura, A search for clustering among the meteoroid impacts detected by the Apollo lunar seismic network. Icarus 91, 315-325 (1991)

M.P. Panning, E. Beucler, M. Drilleau, A. Mocquet, P. Lognonné, W.B. Banerdt, Verifying single-station seismic approaches using Earth-based data: preparation for data return from the InSight mission to Mars. Icarus 248, 230-242 (2015). https://doi.org/10.1016/j.icarus.2014.10.035

M.P. Panning, P. Lognonné, W.B. Banerdt, R. Garcia, M. Golombek, S. Kedar, B. Knapmeyer-Endrun, A. Mocquet, N.A. Teanby, J. Tromp, R. Weber, E. Beucler, J.-F. Blanchette-Guertin, M. Drilleau, T. Gudkova, S. Hempel, A. Khan, V. Lekic, A.-C. Plesa, A. Rivoldini, N. Schmerr, Y. Ruan, O. Verhoeven, C. Gao, U. Christensen, J. Clinton, V. Dehant, D. Giardini, D. Mimoun, W.T. Pike, S. Smrekar, M. Wieczorek, M. Knapmeyer, J. Wookey, Planned products of the Mars structure service for the InSight mission to Mars. Space Sci. Rev. (2017). https://doi.org/10.1007/s11214-016-0317-5

J. Peterson, Observations and modeling of seismic background noise. USGS Open File Report 93-322, available online: https://pubs.usgs.gov/of/1993/0322/report.pdf, 94 pages (1993)

R.J. Phillips, Expected rates of Marsquakes, in Scientific Rationale and Requirements for a Global Seismic Network on Mars. LPI Tech. Rep. 91-02 LPI/TR-91-02, pp. 35-38, Lunar and Planet. Inst., Houston, TX (1991)

J.B. Plescia, Recent flood lavas in the Elysium region of Mars. Icarus 88, 465-490 (1990)

A.-C. Plesa, N. Tosi, M. Grott, D. Breuer, Thermal evolution and Urey ratio of Mars. J. Geophys. Res., Planets 120, 995-1010 (2015). https://doi.org/10.1002/2014JE004748

A.C. Plesa, M. Grot, N. Tosi, D. Breuer, T. Spohn, M. Wieczorek, How large are present-day heat flux variations across the surface of Mars? J. Geophys. Res. (2016). https://doi.org/10.1002/2016JE005126

A.-C. Plesa, M. Knapmeyer, M. Golombek, D. Breuer, M.Grott.N. Tosi, Present- day Mars' seismicity predicted from 3-D thermal evolution models of interior dynamics (expanded abstract), in 48th Lunar and Planetary Science (Lunar and Planetary Institute, Houston, 2017). Abstract \#1906

A.-C. Plesa, M. Knapmeyer, M.P. Golombek, D. Breuer, M. Grott, P. Lognonne, N. Tosi, R.C. Weber, Presentday Mars' seismicity predicted from 3D thermal evolution models of interior dynamics. Geophys. Res. Lett. 45, 2580-2589 (2018). https://doi.org/10.1002/2017GL076124

A.T. Polit, R.A. Schultz, R. Soliva, Geometry, displacement-length scaling, and extensional strain of normal faults on Mars with inferences on mechanical stratigraphy of the Martian crust. J. Struct. Geol. 31, 662-673 (2009). https://doi.org/10.1016/j.jsg.2009.03.016 
C.F. Richter, An instrumental earthquake magnitude scale. Bull. Seismol. Soc. Am. 25(1), 1-32 (1935)

A.T. Ringler, C.R. Hutt, Self-noise models of seismic instruments. Seismol. Res. Lett. 81(6), 972-983 (2010)

A. Rivoldini, T. van Hoolst, O. Verhoeven, A. Mocquet, V. Dehant, Geodesy constraints on the interior structure and composition of Mars. Icarus 213, 451-472 (2011). https://doi.org/10.1016/j.icarus.2011. 03.024

G.P. Roberts, B. Matthews, C. Bristow, L. Guerrieri, J. Vetterlein, Possible evidence of paleo-marsquakes from fallen boulder populations, Cerberus Fossae, Mars. J. Geophys. Res. 117(E2), 003816 (2012)

C. Sanloup, A. Jambon, P. Gillet, A simple chondritic model of Mars. Phys. Earth Planet. Inter. 112(1-2), 43-54 (1999). https://doi.org/10.1016/S0031-9201(98)00175-7

N.C. Schmerr, M.E. Banks, I.J. Daubar, The seismic signatures of impact events on Mars: implications for the InSight lander, in Lunar and Planetary Science Conference, vol. 47 (2016). Abstract 1320

G. Schubert, T. Spohn, Thermal history of Mars and the sulfur content of its core. J. Geophys. Res. 95, 14095-14104 (1990)

G. Schubert, S.C. Solomon, D.L. Turcotte, M.J. Drake, N.H. Sleep, Origin and thermal evolution of Mars, in Mars, ed. by H. Kieffer, B. Jakosky, C. Snyder, M. Matthews (University of Arizona Press, Tucson, 1993), pp. 147-183

R.A. Schultz, Fault-population statistics at the Valles Marineris Extensional Province, Mars: implications for segment linkage, crustal strains, and its geodynamical development. Tectonophysics 316(1), 169-193 (2000)

B.E. Shaw, Initiation propagation and termination of elastodynamic ruptures associated with segmentation of faults and shaking hazard. J. Geophys. Res. 111, B08302 (2006). https://doi.org/10.1029/ 2005JB004093

K.J. Smart, D.A. Ferrill, S.L. Colton, En echelon segmentation of wrinkle ridges in Solis Planum, Mars, and implications for counter-clockwise rotation of shortening direction, in Lunar Planet. Sci. Conf., vol. 37 (2006), pp. 1-2

D.E. Smith, M.T. Zuber, H.V. Frey, J.B. Garvin, J.W. Head, D.O. Muhleman, G.H. Pettengill, R.J. Phillips, S.C. Solomon, H.J. Zwally et al., Mars Orbiter laser altimeter: Experiment summary after the first year of global mapping of Mars. J. Geophys. Res. 106, 23,689-23,722 (2001). https://doi.org/10.1029/ 2000JE001364

F. Sohl, T. Spohn, The interior structure of Mars: implications from SNC meteorites. J. Geophys. Res. 102, 1613-1636 (1997). https://doi.org/10.1029/96JE03419

S.C. Solomon, D.L. Anderson, W.B. Banerdt, R.G. Butler, P.M. Davis, F.K. Duennebier, Y. Nakamura, E. Okal, R.J. Phillips, Scientific rationale and requirements for a global seismic network on Mars, LPI Tech. Rep. No. 91-02. Lunar and Planetary Institute, Houston, TX (1991)

T. Spohn, M. Grott, S.E. Smerkar, C. Krause, T. Hudson (The HP3 Instrument Team) Measuring the Martian Heat Flow Using the Heat Flow and Physical Properties Package (HP3), in 45th Lunar and Planetary Science Conference, The Woodlands, TX, USA (2014)

T. Spohn, M. Grott, S.E. Smrekar, J. Knollenberg, T.L. Hudson, C. Krause, N. Müller, J. Jänchen, A. Börner, T. Wippermann, O. Krömer, R. Lichtenheldt, L. Wisniewski, J. Grygorczuk, M. Fittock, S. Reershemius, T. Spröwitz, E. Kopp, I. Walter, A.-C. Plesa, D. Breuer, P. Morgan, W.B. Banerdt, The Heat Flow and Physical Properties Package (HP3) for the InSight Mission. Space Sci. Rev. 214(5), 1-33 (2018). https://doi.org/10.1007/s11214-018-0531-4

S.C. Stähler, K. Sigloch, Fully probabilistic seismic source inversion-Part 1: Efficient parameterisation. Solid Earth 5(2), 1055-1069 (2014). https://doi.org/10.5194/se-5-1055-2014

S.C. Stähler, K. Sigloch, Fully probabilistic seismic source inversion-Part 2: Modelling errors and station covariances. Solid Earth 7(6), 1521-1536 (2016). https://doi.org/10.5194/se-7-1521-2016

Standard for the Exchange of Earthquake Data (SEED) Manual (FDSN Publications, 2012) http://www.fdsn. org/media/_s/publications/SEEDManual_V2.4.pdf. Last accessed 15 Nov 2018

M.W. Stirling, S.G. Wesnousky, K. Shimazaki, Fault trace complexity, cumulative slip, and the shape of the magnitude-frequency distribution for strike-slip faults: a global survey. Geophys. J. Int. 124, 833-868 (1996). https://doi.org/10.1111/j.1365-246X.1996.tb05641.x

G.J. Taylor, The bulk composition of Mars. Geochemistry 73, 401-420 (2013)

G.J. Taylor, W. Boynton, J. Brückner, H. Wänke, G. Dreibus, K. Kerry, J. Keller, R. Reedy, L. Evans, R. Starr, S. Squyres, S. Karunatillake, O. Gasnault, S. Maurice, C. d’Uston, P. Englert, J. Dohm, V. Baker, D. Hamara, D. Janes, A. Sprague, K. Kim, D. Drake, Bulk composition and early differentiation of Mars. J. Geophys. Res. 111, E03S10 (2006). https://doi.org/10.1029/2005JE002645

J. Taylor, N.A. Teanby, J. Wookey, Estimates of seismic activity in the Cerberus Fossae region of Mars. J. Geophys. Res. E 118, 2570-2581 (2013)

N.A. Teanby, Predicted detection rates of regional-scale meteorite impacts on Mars with the InSight shortperiod seismometer. Icarus 256, 49-62 (2015). https://doi.org/10.1016/j.icarus.2015.04.012 
N.A. Teanby, J. Wookey, Seismic detection of meteorite impacts on Mars. Phys. Earth Planet. Inter. 186, 70-80 (2011). https://doi.org/10.1016/j.pepi.2011.03.004

C. Tong, B.L.N. Kennett, Towards the identification of later seismic phases. Geophys. J. Int. 123, 948-958 (1995)

M. van Driel, L. Krischer, S.C. Stähler, K. Hosseini, T. Nissen-Meyer, Instaseis: instant global seismograms based on a broadband waveform database. Solid Earth 6, 701-717 (2015). https://doi.org/10.5194/ se-6-701-2015

J. Vaucher, D. Baratoux, N. Mangold, P. Pinet, K. Kurita, M. Grégoire, The volcanic history of central Elysium Planitia: implications for Martian magmatism. Icarus 204, 418-442 (2009)

O. Verhoeven, A. Rivoldini, P. Vacher, A. Mocquet, G. Choblet, M. Menvielle, V. Dehant, T. Van Hoolst, J. Sleewaegen, J.P. Barriot, P. Lognonné, Interior structure of terrestrial planets: modeling Mars' mantle and its electromagnetic, geodetic, and seismic properties. J. Geophys. Res. 110, E04009 (2005). https://doi.org/10.1029/2004JE002271

J. Vetterlein, G.P. Roberts, Structural evolution of the Northern Cerberus Fossae graben system, Elysium Planitia, Mars. J. Struct. Geol. 32, 394-406 (2010). https://doi.org/10.1016/j.jsg.2009.11.004

R.C. Weber, B.G. Bills, C.L. Johnson, A simple physical model for deep moonquake occurrence times. Phys. Earth Planet. Inter. 182, 152-160 (2010). https://doi.org/10.1016/j.pepi.2010.07.009

M.A. Wieczorek, M.T. Zuber, The thickness of the Martian crust: improved constraints from geoid-totopography ratios. J. Geophys. Res. 109(E1), E01009 (2004). https://doi.org/10.1029/2003JE002153

P. Withers, G.A. Neumann, Enigmatic northern plains of Mars. Nature 410, 651 (2001)

M. Yamada, H. Kumagai, Y. Matsushi, T. Matsuzawa, Dynamic landslide processes revealed by broadband seismic records. Geophys. Res. Lett. 40, 2998-3002 (2013). https://doi.org/10.1002/grl.50437

V.N. Zharkov, T.V. Gudkova, Construction of Martian interior model. Sol. Syst. Res. 39, 343 (2005). https:// doi.org/10.1007/s11208-005-0049-7 